\title{
Microstructural changes in an extruded Mg-Zn-Y alloy reinforced by quasicrystalline I-phase by small additions of calcium, manganese and cerium-rich mischmetal
}

\author{
J. Medina ${ }^{a,}$, P. Pérez ${ }^{a}$, G. Garces ${ }^{a}$, D. Tolnai ${ }^{b}$, A. Stark ${ }^{b}$, N. Schell ${ }^{c,}$ P. Adeva ${ }^{a}$, \\ ${ }^{a}$ Department of Physical Metallurgy, National Center for Metallurgical Research (CENIM-CSIC), \\ Avda. Gregorio del Amo 8, 28040 Madrid, Spain
}

${ }^{b}$ Institute of Materials Research, Helmholtz-Zentrum Geesthacht, Max-Planck-Str. 1, 21502 Geesthacht, Germany.

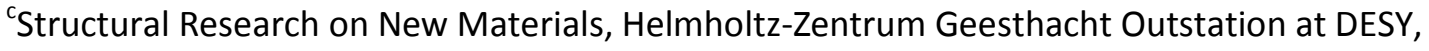
Hamburg, Germany.

[* corresponding author. Tel +34-91-553-8900; fax: +34-91-534-7425;

E-mail address: judit.medina@cenim.csic.es]

\begin{abstract}
The effects of calcium, manganese and cerium-rich mischmetal additions on the microstructure and texture of the extruded Mg-6Zn-1Y (wt. \%) alloy have been investigated. The microstructure of the alloys consisted of a magnesium matrix embedding second phase particles aligned along the extrusion direction. The nature and volume fraction of the second phases depended on the alloying element. Thus, Ce-rich mischmetal promoted the formation of T-phase while calcium additions resulted in the formation of a ternary $\mathrm{Mg}-\mathrm{Zn}$-Ca compound. Only, manganese additions did not affect the existence of the I-phase present in the ternary alloy. The texture was measured and it was found that calcium addition has a significant effect weakening the extrusion texture.
\end{abstract}




\section{Keywords:}

Mg-Zn-Y alloy; microstructural characterization; alloying influence; in-situ; synchrotron radiation diffraction; X-ray diffraction.

\section{Introduction}

Magnesium alloys have great potential for applications in structural parts as they are the lightest metallic structural material. However, their use is still limited because of their low ductility and insufficient strength at room temperature and at high temperatures, and poor corrosion resistance. Many efforts and attempts are being devoted to modifying the composition/microstructure of magnesium alloys to overcome such disadvantages. Thus, the strength of magnesium alloys can be enhanced by adding proper amounts of certain alloying elements and/or by controlling the thermomechanical processing. Accordingly, the mechanical strength of magnesium has increased through the development of a great number of alloy families like Mg-Al-Zn (AZ alloys), Mg-Al-Mn (AM alloys), Mg-Al-Si (AS alloys) or Mg-Al-RE (AE alloys) (RE denotes rare earth elements) [1, 2]. More recently, new high-strength Mg-Zn-Y and Mg-Zn-RE alloys have been developed, whose hardening is attributed to the presence of ternary Mg- $\mathrm{Zn}-\mathrm{Y}$ phases. Depending on the concentration $\mathrm{Zn} / \mathrm{Y}$ ratio, different kinds of second phases are formed: Long period stacked ordered phases (so-called LPSO-phases), W-Phase $\left(\mathrm{Mg}_{3} \mathrm{Zn}_{3} \mathrm{Y}_{2}\right)$, I-phase $\left(\mathrm{Mg}_{3} Z \mathrm{n}_{6} \mathrm{Y}\right)$ and $\mathrm{Mg}_{7} Z \mathrm{n}_{3}$ [3-7]. Among these phases, the quasicrystalline I-phase with its quasiperiodic lattice structure has attracted a lot of attention because of its unique properties as high hardness, thermal stability, high corrosion resistance, low friction coefficient and strong bonding with the magnesium matrix [8-14]. Despite of the good properties of these new $\mathrm{Mg}$ alloys, an additional increase of strength is required to replace Al alloys in structural applications. 
A possible way for enhancing the mechanical properties of $\mathrm{Mg}-\mathrm{Zn}-\mathrm{Y}$ alloys containing the I-phase could be the addition of small amounts of a fourth element. Based on the effect on other magnesium alloys, calcium, manganese and cerium-mischmetal (CeMM) were chosen as alloying elements. Calcium and RE additions refine the microstructure of magnesium alloys and improve the strength at room and high temperatures through the formation of hard intermetallic phases $[2,15-21]$. Moreover, both elements contribute to randomize the basal texture [22]. The complete insolubility of manganese produces a fine dispersion of manganese particles in the magnesium matrix which strengthens the alloy through the refining of the grain size in magnesium alloys [23, 24].

In the present work, the effect of $\mathrm{Ca}, \mathrm{Mn}$ or Ce-rich mischmetal (CeMM) additions on the microstructure of extruded Mg-6Zn-1Y (wt. \%) alloy has been investigated. Special emphasis has been dedicated to determine the nature and stability of the phases present as well as their influence over the texture of the extruded bars. In order to understand the nature of second phases of extruded alloys, characterization of as-cast alloys was at first done.

\section{Experimental}

The master alloy Mg-6Zn-1Y (wt. \%) was prepared by melting pure magnesium, zinc and yttrium in an electric resistance furnace. This alloy was modified by the addition of small amounts of a fourth element: 1\% Ca (wt. \%), $1 \%$ Mn (wt. \%) and $3.5 \%$ CeMM (wt. \%). The CeMM has a RE content of 99.6 (at. \%) distributed as follows: $51.88 \%$ Ce (at. \%), 26.50\% La (at. \%), 5.22\% $\operatorname{Pr}$ (at. \%) and $16.41 \% \mathrm{Nd}$ (at. \%). It is interesting to remark that $1 \% \mathrm{Ca}$ (wt. \%), $1 \% \mathrm{Mn}$ (wt. \%) and $3.5 \%$ Ce-rich mischmetal (wt. \%) additions correspond to around 0.5 at. \% of each element. The alloys were obtained by casting in a cylindrical steel mould of $45 \mathrm{~mm}$ in diameter and $50 \mathrm{~cm}$ in length. 
Designations, nominal and chemical compositions of the alloys determined by micro X-ray fluorescence are listed in Table 1.

Billets were ground to $41 \mathrm{~mm}$ and directly extruded at $300^{\circ} \mathrm{C}$ using an extrusion ratio of 18:1. Microstructural characterization of alloys was carried out by X-ray diffraction (XRD) as well as by optical microscopy (OM). Scanning electron microscopy (SEM) was performed on a Hitachi S-4800 microscope and transmission electron microscopy (TEM) was carried out on a Jeol-2010.

Thermal stability of as-cast alloys was performed by differential scanning calorimetric (DSC) experiments in Setaram SETSYS evolution equipment at a heating rate of $20 \mathrm{~K} / \mathrm{min}$ under argon atmosphere. The samples were heated from room temperature up to $650^{\circ} \mathrm{C}$. Additionally highenergy X-ray diffraction (HEXRD) was performed at the P07 beam-line of PETRA III, at the Deutsches Elektronen-Synchrotron (DESY) during in situ DSC experiments. The samples were encapsulated in stainless steel crucibles. The DSC unit of a DIL 805A/D dilatometer was modified for synchrotron experiments, having a hole allowing the X-ray beam to reach the sample. The energy of the synchrotron X-ray source was $87.1 \mathrm{keV}$ corresponding to a wavelength of 0.01424 $\mathrm{nm}$. The diffraction patterns were collected using a 2D Perkin Elmer XRD1621 flat panel detector with an array of $2048 \times 2048$ pixels, with a $200 \times 200 \mu \mathrm{m}^{2}$ pixel size and located $2350 \mathrm{~mm}$ from the sample. $\mathrm{LaB}_{6}$ standard powder sample was used as a reference to calibrate the acquired diffraction spectra. The samples were exposed to one DSC cycle from room temperature (RT) up to $700^{\circ} \mathrm{C}$ with a heating rate of $20 \mathrm{~K} / \mathrm{min}$. The diffraction patterns observed as Debye-Scherrer rings were collected every $4 \mathrm{~s}$ and then integrated using Fit2D software in order to obtain the diffraction pattern as a function of $2 \theta$. To distinguish between two DSC experiments, DSC measurements run in Setaram equipment will be designated as "conventional DSC experiments" while those obtained by synchrotron radiation will be called "in-situ DSC experiments". 
X-ray diffraction was used for phase identification and texture analysis. Measurements were performed in a Siemens D5000 X-ray diffractometer (XRD) using $\mathrm{Cu}$ Ka radiation. Texture data were analyzed by TextEval software.

Phase characterization, determination of the volume fraction of second phases and grain sizes of all alloys were studied by OM, SEM and TEM and EDS microanalysis. Volume fraction of second phases was estimated by image analysis technique (OPTIMAS software). Statistical measurements of particle and grain sizes were calculated with the software Sigma Scan Pro using OM and SEM micrographs.

Micro-texture analysis of extruded alloys was also done by Electron Backscattered Diffraction (EBSD) technique attached to the SEM equipment. Data of EBSD were analyzed using Channel 5 EBSD software. The samples have a cylindrical symmetry where the reference directions are: ED (extrusion direction), TD (transversal direction) and ND (normal direction). For Orientation Image Mapping the scan size was set at 0.2-0.3 $\mu \mathrm{m}$. High angle grain boundaries $>10^{\circ}$ and low angle grain boundaries $>2^{\circ}$ are represented by black and white lines, respectively.

Metallographical preparation of samples for optical and scanning electron microscopy observation consisted of conventional mechanical polishing, and finishing with a solution of colloidal silica. The grain structure was revealed with a solution of $0.5 \mathrm{~g}$ of picric acid, $0.5 \mathrm{ml}$ of acetic acid, $0.5 \mathrm{ml}$ of water and $25 \mathrm{ml}$ of ethanol. Specimens for transmission electron microscopy were thinned by electrolytic polishing using the reactive mixture of $25 \%$ nitric acid and $75 \%$ methanol at $-20^{\circ} \mathrm{C}$ and $20 \mathrm{~V}$. Then, ion milling at liquid nitrogen temperature was used to remove the fine oxide film formed on the surface. 
EBSD samples required a very carefully metallographical preparation because of the high reactivity of magnesium. Thus, the specimens were ground with 320, 600, 1200 and 2000 grit SiC paper, polished with a solution of colloidal silica in ethanol and finally chemically etched.

\section{Results}

\subsection{Characterization of as-cast alloys}

The microstructure of all alloys consists of magnesium dendrites with different intermetallic phases at the interdendritic spaces resulting from solidification of the liquid enriched in alloying elements. The alloying addition determines the nature of the phases present in the interdendritic regions. The interdendritic regions are constituted by eutectic pockets of binary $\mathrm{Mg}+\mathrm{I}$-phase in the ternary alloy and in the Mn1 alloy, as can be seen in the backscattered electron images of Figures $\mathbf{1 a}$ and $\mathbf{1 b}$. In the case of Mn1 alloy, some fine particles inside the magnesium dendrites are also detected (see Figure 1b). The volume fraction and nature of the second phases existing at the interdendritic space are different for Ca1 and CeMM3.5 alloys. Thus, two different phases can be clearly identified at the interdendritic regions (Figure 1c), a predominant light grey phase and a bright minority phase close to it. The main phase corresponds to a Ca-rich phase without yttrium while the second one is a ternary Mg-Zn-Y compound with the stoichiometry of W-phase. Two phases can be also distinguished inside the interdendritic regions in CeMM3.5 alloy, as observed in Figure 1d. A semiquantitative composition determined by EDS microanalyses reveals that the dark phase contains $\mathrm{Mg}, \mathrm{Zn}$, and $\mathrm{Ce}$, while the bright phase, surrounding the mentioned Ce-rich phase is composed by $\mathrm{Mg}, \mathrm{Zn}$ and $\mathrm{Y}$ with a composition close to that of the $\mathrm{W}$-phase. 
Figure 2 compares isochronal conventional DSC curves. During heating the endothermic peaks can be associated with different transformations. The in-situ synchrotron diffraction patterns obtained at different points in the curve during the heating (see Figure 3) allow identifying the evolution of the phases. Three transformations are detected in the curves. Temperatures of the different transformations are listed in Table 2. Common for all alloys is the last peak, also the most intense, which is produced by the melting of magnesium dendrites. The first transformation for 6-1 and $\mathrm{Mn1}$ alloys (Figure $\mathbf{2 a}$ and $\mathbf{2 b}$ ) is close to $450^{\circ} \mathrm{C}$ and it is related to the dissolution of the I-phase. This temperature coincides rather well with the dissolution temperature established for the Iphase in Mg-Zn-Y and Mg-Zn-Y-Zr alloys [8, 11, 25]. As can be seen in Figure $\mathbf{3 a}$ and Figure $\mathbf{3 b}$, this phase is initially present in the as-cast ingots, remaining stable up to about $440^{\circ} \mathrm{C}$. Above this temperature, peaks due to I-phase disappear. It is interesting to note that the DSC peak associated with I-phase dissolution is double in the case of the Mn1 alloy since the peak is preceded by a prominent shoulder. The second endothermic peak for 6-1 and Mn1 alloys (Figure 2a and 2b) corresponds to W-phase dissolution. As shown in the in-situ synchrotron diffraction pattern of Figure $\mathbf{3 a}$ and $\mathbf{3 b} \mathbf{b}, \mathrm{W}$-phase is not initially present in either the as-cast 6-1 ingot or the Mn1 alloy. Coinciding with I-phase dissolution the peaks due to the W-phase commence to appear, indicating that this phase is formed at the expense of the dissolved I-phase. The W-phase remains stable until $470-480^{\circ} \mathrm{C}$, very close to that reported for melting of W-phase in Mg-Zn-Y-Zr alloys $[9,25]$.

In the case of the Ca1 alloy the first peak in the DSC curve starts at $388^{\circ} \mathrm{C}$ and it is associated with the fusion of the Ca-rich phase. According to synchrotron diffraction patterns this phase remains stable until $386^{\circ} \mathrm{C}$ (see Figure 3c). These results are consistent with previous studies in Mg-Zn-Ca and Mg-Zn-Ca-CeMM systems which determined the melting point of $\mathrm{Mg}_{6} \mathrm{Zn}_{3} \mathrm{Ca}_{2}$ to be $390^{\circ} \mathrm{C}[26$, 27]. The second peak is broader and much less pronounced (Figure $\mathbf{2 c}$ ) and it appears at about $470^{\circ} \mathrm{C}$. This transformation is associated with the dissolution of W-phase as can be observed in 
Figure 3c. The conventional DSC curve for CeMM3.5 alloy exhibits three transformations associated with each one of the three phases identified in the as-cast structure. According to synchrotron diffraction patterns of Figure $\mathbf{3 d}$, the first transformation corresponds to W-phase. This phase exists in the as-cast ingots and remains stable until $490^{\circ} \mathrm{C}$. The second transformation in DSC curve (see Figure 2d) corresponds with the Ce-rich phase which is stable until $520^{\circ} \mathrm{C}$. Several peaks in the synchrotron diffraction pattern coincide with those detected for a ternary Mg-Zn-Ce compound, named T-phase, in Mg-Zn-RE alloys [28-31].

During the thermal experiments, the peak associated to I-phase has been detected only in 6-1 and Mn1 alloys. This indicates that calcium and cerium mischmetal additions modify the stability range of the quasicrystalline I-phase. In addition, dissolution of the I-phase during heating is simultaneous to the appearance of W-phase which during further heating is melted in the temperature range $470-505^{\circ} \mathrm{C}$. It is interesting to note that melting of W-phase takes place in $6-1$ and CeMM3.5 alloy at temperatures at least $20^{\circ} \mathrm{C}$ above those found for $\mathrm{Mn} 1$ and $\mathrm{Ca} 1$ alloys. EDS microanalyses reveal that such behavior is due to compositional changes in the W-phase. In the case of $\mathrm{Mn} 1$ and CeMM3.5 alloys the atomic $\mathrm{Zn} / \mathrm{Y}$ ratio of $\mathrm{W}$-phase is close to 1.5 and the melting temperature close to $500^{\circ} \mathrm{C}$, in good agreement with data reported in the literature. On the other hand, the atomic $\mathrm{Zn} / \mathrm{Y}$ ratio is close to 2 in the $\mathrm{W}$-phase of Ca1 and Mn1 alloys, being the melting point close to $485^{\circ} \mathrm{C}$.

\subsection{Characterization of extruded alloys}

\subsubsection{Phases characterization}

The microstructures of the four extruded alloys consist of a magnesium matrix and a high volume fraction of second-phase particles, aligned along the extrusion direction, as shown by the longitudinal sections in Figure 4. The volume fraction of second phases is 5.8 \% for $6-1$ alloy, $7.8 \%$ 
for Mn1 alloy, $8.3 \%$ for Ca1 alloy and $14.3 \%$ for CeMM3.5 alloy (see Table 3). It is evident that alloying additions result in an increase in the volume fraction of second phases, especially for the CeMM-containing alloy.

XRD patterns of extruded Mg-Zn-Y alloys are shown in Figure 5. The main diffraction peaks are always indexed as magnesium while minor peaks correspond to the different second phases. In addition, relatively intense peaks due to the I-phase are found for 6-1 and Mn1 alloys. Moreover, small peaks attributed to metallic manganese are also detected in the XRD pattern. In the case of Ca1 and CeMM3.5 alloys the I-phase is absent in XRD patterns and only the W-phase is common for both alloys. For Ca1 alloy the predominant phase coincides with the $\mathrm{Mg}_{6} \mathrm{Zn}_{3} \mathrm{Ca}_{2}$. In the XRD pattern of CeMM3.5 alloy most of the minor peaks do not match with any known phase according to the Joint Committee on Powder Diffraction Standards (JCPDS). Nevertheless, they could be attributed to the T-phase because the peaks match rather well with those experimentally found for T-phase in several Mg-Zn-RE alloys and Mg-Zn-Nd-Zr alloys [28-30].

Identification of the different second phases, carried out by XRD, was confirmed by TEM observations. Bright field images of 6-1 alloy (Figure $6 \mathbf{a}$ and $\mathbf{6 b}$ ) evidence that coarse particles of about $600 \mathrm{~nm}$ are preferentially located at grain boundaries while small second-phase particles ranging from 10 to $60 \mathrm{~nm}$ (average grain size of about $18 \mathrm{~nm}$ ) are inside magnesium grains and at grain boundaries as well. The selected area diffraction pattern taken from coarse particles of Figure 6 exhibits the typical three-fold-symmetry of quasicrystalline I-phase (see Figure 6a). Identification as I-phase was equally corroborated by EDS data that demonstrate it corresponds to a $\mathrm{Zn}$-rich ternary compound containing also magnesium and yttrium with an atomic $\mathrm{Zn} / \mathrm{Y}$ ratio close to 6 . These results confirm this phase is the quasicrystalline I-phase $\left(\mathrm{Mg}_{3} Z n_{6} Y\right)$ in good agreement with XRD results. 
In the case of Mn1 alloy, the composition of coarse second phase particles (from 0.5 to $6 \mu \mathrm{m}$ in size) corresponds to a $\mathrm{Zn}$-rich phase with a significant yttrium concentration (10 at. \%) and small amounts of manganese (1.5 at. \%). The atomic $\mathrm{Zn} / \mathrm{Y}$ ratio corresponds to that of the I-phase. The presence of manganese in the I-phase suggests that manganese can substitute zinc atoms in the Iphase lattice because their atomic radii are very close. Figure $7 \mathrm{a}$ is a bright field image of coarse second phases located at grain boundaries. The corresponding SAEDP shows a 5 -fold symmetry typical of quasicrystalline phases, confirming they are I-phase, in good agreement with XRD results. At higher magnifications, fine particles with different morphologies can be resolved within the magnesium matrix (Figure 7b). Each morphology is, generally, associated with a phase. Spherical particles around $40 \mathrm{~nm}$ in size correspond to I-phase while the smaller particles, ranging between 5 to $40 \mathrm{~nm}$ in size, Figure 7c, correspond to a Mn-rich phase totally free of yttrium whose manganese content shifts from 6 to 35 at. \%. Finally, plate precipitates, $30 \mathrm{~nm}$ width and $150 \mathrm{~nm}$ length, are enriched in zinc, so they correspond to a $\mathrm{Mg}$ - $\mathrm{Zn}$ intermetallic phase (see particles labeled in Figures $\mathbf{7 b}$ and $\mathbf{7 d}$ ). Furthermore, considering their morphology, these particles could correspond with those needle-like $\mathrm{Mg}_{4} \mathrm{Zn}_{7}$ precipitates found in $\mathrm{Mg}-3.5 \mathrm{Zn}-0.6 \mathrm{Gd}$ alloy [32].

In the Ca-containing alloy three different second phases are found. According to microanalysis results and SAED patterns, coarse particles appearing as strings aligned along the extrusion direction, as illustrated in Figure 8a, correspond to the ternary $\mathrm{Mg}_{6} \mathrm{Zn}_{3} \mathrm{Ca}_{2}$ compound. This phase has a hexagonal structure with $\mathrm{P} 63 / \mathrm{mmc}(194)$ space group and $\mathrm{Sc}_{3} \mathrm{Ni}_{11} \mathrm{Si}_{4}$ prototype. Zhang et al. determined that lattice parameters increased linearly with increasing magnesium content [33]. Assuming that the lattice parameters $\mathrm{Mg}_{6} \mathrm{Zn}_{3} \mathrm{Ca}_{2}$ are: $\mathrm{a}=0.9958 \mathrm{~nm}$ and $\mathrm{c}=1.0395 \mathrm{~nm}$, the SADPs

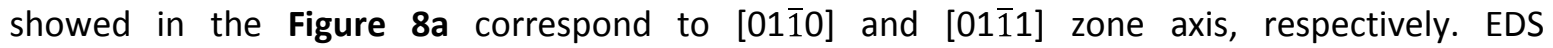
microanalysis of other coarse second phases, shown in Figure $\mathbf{8 b}$, gives the composition of a Cafree ternary $\mathrm{Mg}-\mathrm{Zn}-\mathrm{Y}$ phase, with an atomic $\mathrm{Zn} / \mathrm{Y}$ ratio close to 1.5 that agrees with the 
stoichiometry of the $\mathrm{W}$-phase $\left(\mathrm{Mg}_{3} \mathrm{Zn}_{3} \mathrm{Y}_{2}\right)$ detected by XRD. The structure of the $\mathrm{W}$-phase was first reported by Padezhnova et al. who reported a partially ordered AIMnCu 2 -type FCC structure with a $=0.6848 \mathrm{~nm}$. Thus, the SADPs showed in Figure $\mathbf{8 b}$ correspond to the [011] and [1111] zone axes. Finally, fine spherical precipitates with an average size of $30 \mathrm{~nm}$ in size, visible in Figure $\mathbf{8 b}$, have been identified as I-phase. Although their small size precludes an accurate determination of their composition, microanalysis data proved the presence of magnesium, zinc and yttrium with an atomic $\mathrm{Zn} / \mathrm{Y}$ atomic ratio close to 6.

The microstructure of CeMM-containing alloy shows the highest volume fraction of second phases. Particles of different contrast and size are resolved in Figure 4d. According to XRD results, the predominant phase is the T-phase. This phase has been recently reported existing in a wide range of compositions in $\mathrm{Mg}-\mathrm{Zn}-\mathrm{RE}$ alloys. Huang et al. proposed $\left(\mathrm{Mg}_{1-\mathrm{x}} \mathrm{Zn}_{\mathrm{x}}\right)_{11} \mathrm{Ce}$ as the chemical formula of T-phase in ternary Mg-Zn-Ce alloys. The compositional range for the zinc content in the T-phase is very broad, varying from 9.6 to 43.6 at. \%. On the other hand, the Ce content is kept nearly constant around 8.5 at. \% [34]. Similar results have been reported when cerium is replaced by mischmetal $[35,36]$ Thus, the zinc content ranged from 12 to 38 at. \% while mischmetal content was around 7-8 at. \% . EDS microanalyses carried out in the present study reveal that the T-phase contains about 7 at. \% of RE elements while the zinc content remains between 22 and 27 at. \%, in excellent agreement with the data described in previous studies [31, 34-36]. It has been stated that T phase has a c-centered orthorhombic structure whose lattice parameters depend on the zinc and RE content. Figure 9a shows a particle identified as T-phase and the corresponding SAED pattern taken from [011] zone axis assuming $a=0.999 \mathrm{~nm}, \mathrm{~b}=1.146 \mathrm{~nm}$ and $\mathrm{c}=0.976 \mathrm{~nm}$ as lattice parameters [34].

Finally, the brighter particles in Figure $\mathbf{4} \mathbf{d}$ were identified as $\mathbf{W}$-phase since microanalysis results indicated no presence of RE elements, and the atomic $\mathrm{Zn} / \mathrm{Y}$ ratio is that corresponding to the $\mathrm{W}$ - 
phase. Small spherical precipitates are also present inside the Mg matrix as shown in Figure 9b. Although they are very fine, microanalysis data prove they are enriched in zinc and yttrium with no content of lanthanide elements.

These results are in good agreement with XRD patterns of Figure $\mathbf{5}$ and coincide rather well with those observed in as-cast alloys. Therefore, extrusion at $300^{\circ} \mathrm{C}$ has not modified the nature of second phases.

\subsubsection{Grain structure}

The microstructure of extruded alloys are presented in etched longitudinal sections of Figure 10. Fine equiaxed recrystallized and elongated coarse un-recrystallized areas are present in all alloys. Fine-grained areas predominate always over un-recrystallized regions but their size and volume fraction depend on the element added. The average grain size of recrystallized grains in 6-1 alloy is $3.6 \mu \mathrm{m}$ while coarse-grained areas, 2 to $20 \mu \mathrm{m}$ width and 28 to $170 \mu \mathrm{m}$ length, represent the $6.4 \%$ of the total volume (see Figure 10a). An analogous microstructure is found for the Mn1 alloy, but the volume fraction and size of un-recrystallized areas are higher (see Figure 10b). Thus, the volume fraction is $8.4 \%$ while the width of coarse un-recrystallized grains ranges between 2 and $40 \mu \mathrm{m}$ and their length between 24 and $400 \mu \mathrm{m}$. In addition, the grain size of recrystallized grains is $2.1 \mu \mathrm{m}$, almost half that found for fine-grained areas in the ternary 6-1 alloy. When CeMM is added the volume fraction of un-recrystallized zones is reduced up to $5.8 \%$, and the grain size of recrystallized regions is $1.9 \mu \mathrm{m}$ (see Figure 10c). The Ca1 alloy is that exhibiting the more homogeneous microstructure because most of the magnesium matrix recrystallizes during the extrusion, leading to an equiaxed fine-grained microstructure with an average grain size of approximately $4.5 \mu \mathrm{m}$ in which un-recrystallized areas are practically absent (see Figure 10d). Table 3 summarizes the different microstructural features found for these alloys. 


\subsubsection{Texture analysis}

The texture and microtexture on longitudinal sections along the extrusion direction for all alloys are presented in Figure $\mathbf{1 1}$ and Figure 12, respectively. The pole figures of extruded 6-1 alloy show a relatively weak basal texture in which the basal planes are parallel to the extrusion direction, although they can be rotated from 0 to $90^{\circ}$ in the TD plane which is reflected in a maximum intensity of 9 in the $\{10 \overline{1} 0\}$ figure pole, because independently of rotation degree of basal planes the prismatic $\{10 \overline{1} 0\}$ planes are always perpendicular (Figure 11a). The effect of manganese and CeMM additions has a negligible effect on this texture since it is essentially the same. Even the maximum intensity in the $\{10 \overline{1} 0\}$ figure pole is 9 for all these alloys. Only calcium addition has a marked effect in texture. Texture remains basal, but very weak, because the maximum intensity is reduced to 3. The maximum intensities in EBSD maps of Figure $\mathbf{1 2}$ are highly conditioned by the amount of un-recrystallized regions present in the measured region. The calculated pole figures agree rather well with macrotexture measurements. As expected, coarse un-recrystallized regions correspond to grains with their basal planes parallel to the extrusion direction (red and green coloured grains in EBSD maps). Consequently, they contribute greatly to the overall texture, increasing sharply the basal microtexture. Furthermore, EBSD maps also evidence that the coarsest un-recrystallized grains present regions with certain misorientation to each other, as observed in Figure 12a.

\section{Discussion}

The results clearly prove that small amounts of a fourth element to the ternary 6-1 alloy are enough to induce significant changes in the microstructure of the alloy. The main microstructural effects as result of the addition of 0.5 at. \% of manganese, calcium or CeMM can be summarized as follows: 
1) The stability of the I-phase is not modified by manganese additions, but this element promotes a fine dispersion of $\mathrm{Mn}$ and $\mathrm{MgZn}$ precipitates within the magnesium grains. After extrusion, the grain size of recrystallized regions is reduced while the volume fraction of un-recrystallized regions is kept relatively constant. However, the length of un-recrystallized grains is substantially increased. Finally, manganese addition has a negligible effect on texture.

2) $\mathrm{Ca}$ addition prevents the formation of coarse I-phase particles, leading instead to a higher volume fraction of coarse $\mathrm{Mg}_{6} \mathrm{Zn}_{3} \mathrm{Ca}_{2}$ and $\mathrm{W}$-phase particles. The magnesium matrix in the extruded alloy is completely recrystallized, leaving only residual un-recrystallized regions. The grain size of recrystallized areas is slightly higher that of the 6-1 alloy. Finally, calcium addition randomizes the texture of the alloy.

3) CeMM addition also precludes I-phase formation. A high volume fraction of T-phase is developed and minor amounts of W-phase. Grain size of recrystallized areas is refined and the fraction of un-recrystallized regions is lower than in the ternary alloy. Nevertheless, unrecrystallized grains are much narrower and elongated than those of the 6-1 alloy, but the intensity of texture is similar.

It can be clearly noticed that additions have two kinds of effects; those associated with the nature of the second phases and those related to the grain size and texture of the magnesium matrix in the extruded alloys.

\subsection{Effects over the second phases}

Major effect of the addition of manganese, calcium and CeMM concerns the nature of second phases. This effect can be clearly viewed in DSC curves, XRD and HEXRD patterns. Mg-rich dendrites solidify first during cooling. Then, the remaining melt enriched in the alloying elements, solidifies, leading to the formation of the different second phases located at the interdendritic 
arms. In the ternary Mg-Zn-Y system, the thermodynamically stable phase under equilibrium conditions depends on the $\mathrm{Zn} / \mathrm{Y}$ ratio in the alloy. Given the stoichiometry of the I-phase it could be expected that the weight $\mathrm{Zn} / \mathrm{Y}$ ratio should be close to 4.4 (equivalent to 6 in atomic percentage). However, the weight $\mathrm{Zn} / \mathrm{Y}$ ratio in the ternary $6-1$ alloy is 6 . Such discrepancy arises from the fact that $\mathrm{Zn}$ and $\mathrm{Y}$ can be dissolved in the magnesium matrix and can be forming more than one phase in the alloy, as well. The criterion usually found in the literature is based on the weight $\mathrm{Zn} / \mathrm{Y}$ ratio in the alloy although some authors make reference to an atomic $\mathrm{Zn} / \mathrm{Y}$ ratio. Based on experimental data, it has been stated that the I-phase is formed when the weight $\mathrm{Zn} / \mathrm{Y}$ ratio is 5-7 (corresponding to an atomic $\mathrm{Zn} / \mathrm{Y}$ ratio of 6.8-9.5), as in the case of 6-1 alloy [3, 37]. Xu et al. reported a weight $\mathrm{Zn} / \mathrm{Y}$ ratio larger than 4.4 to form exclusively $\alpha-\mathrm{Mg}$ and I-phase [4]. Finally, Zhang et al. established that the only phase formed on alloys with $5.5 \mathrm{Zn}$ (wt.\%) and low yttrium contents ( 0.74 and $1.35 \mathrm{wt} . \%)$ is the I-phase [9]. From these data, the interval of weight $\mathrm{Zn} / \mathrm{Y}$ ratio to form exclusively I-phase would be 4-7.4 (corresponding to an atomic $\mathrm{Zn} / \mathrm{Y}$ ratio of 5.4-10) instead of the 5-7 interval proposed in previous works.

According to isothermal Mg-Zn-Y phase diagram sections $[38,39] \alpha-\mathrm{Mg}$ is the first phase to solidify in the 6-1 alloy, then the W-phase could form directly from the melt through the following eutectic reaction:

$\mathrm{L} \rightarrow \mathrm{Mg}+\mathrm{W}\left(\right.$ at $\left.530^{\circ} \mathrm{C}\right)$

After that, in the subsequent cooling the I-phase is formed by the reaction:

$\mathrm{Mg}+\mathrm{W} \rightarrow \mathrm{W}+\mathrm{I}\left(\right.$ at $\left.448^{\circ} \mathrm{C}\right)$

Nevertheless, W-phase was not detected by in-situ HEXRD measurements during cooling from the melt at $20 \mathrm{~K} / \mathrm{min}$ in DSC tests. This could be attributed to solidification proceeds far from equilibrium conditions and/or the volume fraction of W-phase was too small to be detected. Furthermore, the narrow temperature interval between I-phase and W-phase could lead directly 
to the formation of I-phase through the direct eutectic reaction of the melt remaining at the interdendritic regions [40].

During heating in DSC tests, however, the W-phase appears close to $440^{\circ} \mathrm{C}$, once I-phase dissolves, indicates that a transformation during heating from I- to W-phase takes place, agreeing with the observations of Liu et al. [41]. These authors conclude that I-phase dissolves progressively to transform into W-phase.

Manganese addition has no influence on the stability field of the I-phase. This must be related to the complete insolubility of manganese in the magnesium lattice. Consequently, during cooling it tends to segregate as fine round $\mathrm{Mn}$ particles inside the magnesium grains but also decorating the grain boundaries, as observed in Figure 7. EDS microanalysis data reveal that these $\mathrm{Mn}$-rich particles contain certain amounts of zinc which can be attributed to partial substitution of manganese atoms by zinc atoms in the manganese lattice as result of the similarity of their respective atomic radii (1.26 $\AA$ for manganese and $1.38 \AA$ for zinc) and mutual solubility. In the same way, manganese atoms can replace zinc atoms, about 1.5 at. \%, in both coarse and fine Iphase particles, as checked by EDS microanalyses. Since not all the zinc is consumed to form the stoichiometric I-phase, the rest of the zinc remains dissolved in the magnesium matrix and the excess precipitates as intermetallic MgZn laths within the magnesium grains (see Figures $\mathbf{7 b}$ and 7d) which were not detected in the 6-1 alloy. Mutual replacing of manganese and zinc in the different phases and the higher zinc content of the Mn1 alloy account for the higher volume fraction of second phases found in this alloy compared to that of 6-1 alloy.

In the case of alloys with calcium or CeMM additions, DSC curves prove the formation of phases other than quasicrystalline I-phase. Calcium addition results in the formation of $\mathrm{Mg}_{6} \mathrm{Zn}_{3} \mathrm{Ca}_{2}$ compound and W-phase at the interdendritic spaces. According to DSC curves, solidification of Wphase takes place, because of its higher melting point, while $\mathrm{Mg}_{6} \mathrm{Zn}_{3} \mathrm{Ca}_{2}$ solidifies at much lower 
temperature. The absence of I-phase could be an indication that calcium addition shifts the atomic $\mathrm{Zn} / \mathrm{Y}$ ratio in the ternary 6-1 alloy towards the value for exclusive $\mathrm{W}$-phase formation $(\mathrm{Zn} / \mathrm{Y}=1.5-2)$. It could be assumed that a big atom like calcium could substitute yttrium rather than zinc in Wphase lattice. However, no calcium is detected in $\mathrm{W}$-phase, so calcium cannot reduce the $\mathrm{Zn} / \mathrm{Y}$ ratio. Thus, the only way to explain the origin of W-phase instead of I-phase is by modifying the stability range of the phases with respect to the ternary $M g-Z n-Y$ phase diagram. After solidification of magnesium dendrites, almost all yttrium is consumed for W-phase formation, so the melt becomes enriched in zinc and calcium, which solidifies like $\mathrm{Mg}_{6} \mathrm{Zn}_{3} \mathrm{Ca}_{2}$ in subsequent cooling. In agreement with microanalysis data, magnesium dendrites do not contain calcium because of the almost complete immiscibility of calcium in magnesium from high temperatures (just 0.82 at. $\%$ at $516^{\circ} \mathrm{C}$ ), so all calcium is destined to form $\mathrm{Mg}_{6} \mathrm{Zn}_{3} \mathrm{Ca}_{2}$. T- and $\mathrm{W}$-phase are the second phases formed during casting of CeMM3.5 alloy. Most of the elements constituting CeMM are insoluble in magnesium lattice, so during the solidification process the magnesium dendrites are practically free of RE elements, and only minor amounts of zinc and yttrium dissolve. Thus, the melt surrounding the magnesium dendrites is enriched in RE elements, zinc and yttrium. From this melt, the T-phase is the first solidifying phase, as can be noticed in DSC curves. Due to the stoichiometry of this phase, with a high $\mathrm{Mg} / \mathrm{RE}$ ratio [31], small RE additions lead to a high volume fraction of T-phase. Once T-phase solidifies, the remaining melt only contains magnesium, zinc and yttrium, so only phases predicted by the ternary Mg-Zn-Y phase diagram could be formed during subsequent cooling. T-phase formation requires high zinc contents, so in the melt the $\mathrm{Zn} / \mathrm{Y}$ becomes lower than the critical value to form I-phase, creating W-phase instead.

The presence of fine I-phase particles within magnesium grains observed in the extruded alloys due to the excess of yttrium and zinc in the magnesium dendrites precipitates during the holding time at the extrusion temperature. 


\subsection{Effects on the microstructure of the alloy}

The distribution of second phases as well as the grain sizes and texture of the magnesium matrix depend on the alloying addition. The size of coarse second-phase particles in extruded alloys is given by morphology, composition and dimension of the phases constituting the interdendritic arrangements in the as-cast ingot. During the extrusion, magnesium dendrites are soft but their plastic flow is constrained by the second phases placed at the interdendritic regions. Progressively, the magnesium matrix transfers load to the interdendritic regions until they are broken, and the load is released and comes back to the magnesium matrix. Experimental data demonstrate a correlation between the extrusion pressure and the fraction of dynamically recrystallized grains. The lower the pressure, the lower the strain energy stored by the magnesium dendrites, and consequently the occurrence of complete dynamic recrystallization is more difficult.

The low pressure for 6-1 and Mn1 alloys, around $1100 \mathrm{MPa}$, arises from the discontinuous $\mathrm{Mg}+\mathrm{I}$ pockets constituting the narrow interdendritic regions in the as-cast ingots. This results in the distribution of fine second phases aligned along the boundaries of the elongated magnesium dendrites. The volume fraction of un-recrystallized regions is slightly higher in the case of $\mathrm{Mn} 1$ alloy (8.4 \% versus $6.4 \%$ of $6-1$ alloy). This difference is direct evidence that the higher volume fraction of second phases in Mn1 alloy stimulates the nucleation of new recrystallized grains at the magnesium/particle interface through the particle stimulated nucleation mechanism (PSN) [42].

The extrusion pressure for the CeMM3.5 alloy is only 150 MPa higher than that for Mn1 and 6-1 alloys in spite of duplicate the volume fraction of second phases at the interdendritic regions. This means that T-phase is brittle and breaks easily during the extrusion as very coarse particles.

Although the volume fraction of second phases in the Ca1 alloy is slightly higher than that measured in the Mn1 alloy, the pressure attained during the extrusion is $1700 \mathrm{MPa}$. Such high 
value has to be attributed to the continuity of second phases in the interdendritic region and the high strength of the predominant second phase $\left(\mathrm{Mg}_{6} \mathrm{Zn}_{3} \mathrm{Ca}_{2}\right)$. In this material, the strain accumulated is so high that it constitutes the driving force not only for the complete recrystallization of the magnesium matrix but also for subsequent grain coarsening. In fact, the grain size of Ca1 alloy is the largest among all the alloys.

The texture of the alloys depends on the recrystallization degree reached in the extruded bars. As can be deduced from EBSD maps, non-recrystallized areas correspond to grains with the basal plane parallel to the extrusion direction, while no preferred orientations are noticed in the recrystallized grains. Thus, texture of fully recrystallized Ca1 alloy is almost random, while the rest of alloys exhibit a basal texture provided mostly by coarse un-recrystallized grains. Especially surprising is the basal texture of CeMM3.5 alloys. Usually, the addition of rare earth elements is reported to exhibit the typical "rare earth" texture represented by a texture component at [1 $2 \overline{1} 1]$ parallel to the extrusion direction [43-45].

The differences observed in grain sizes of recrystallized regions must be considered. The grain size ranges from the $1.9 \mu \mathrm{m}$ of the CeMM3.5 alloy to the $4.4 \mu \mathrm{m}$ of the Ca1 alloy. As previously discussed, nucleation of new recrystallized grains is favoured by coarse particles and/or high strain stored in the magnesium matrix. Furthermore, fine particles could also lessen the recrystallized fraction, because they hinder recrystallization kinetics [46]. Once new grains are formed, further grain growth is mainly controlled by the fine precipitates homogeneously distributed in the magnesium matrix. Different models have been considered to predict the maximum grain size of recrystallized grains. Zener [47] was the first proposing an expression for the critical grain size in the steady state as a function of the volume fraction and the average size of the particles [Equation 1]. Assuming a random distribution of spherical particles acting as pinning points, where $r$ is the radius of particle and $f$ is their volume fraction, the limiting grain size $D$ is given by: 
$\mathrm{D}=\frac{4 \mathrm{r}}{3 \mathrm{f}}$

[Eq. 1]

According to the volume fraction of the fine precipitates in each alloy, the smaller grain size should correspond to the Mn1 alloy, being similar for the rest of the alloys. Since the grain size of recrystallized grains is often underestimated by the Zener model, the model has been modified to get good correlation between the theoretical and experimental values. Among several models proposed, the Hellman-Hillert and Rios models are those more widely used [48, 49]. HellmanHillert model [see Equation 2] takes into account the unpinning of the grain boundary from particles and the effect of grain boundary curvature on grain growth, while Rios model [see Equation 3] considers the energy dissipated during the motion of an interface through the dispersed particles rather than the opposing force proposed by Zener. The grain size of recrystallized grains for both models would be given by:

$\mathrm{D}=\frac{8 \mathrm{r}}{9 \mathrm{f}^{0.93}}$

[Eq. 2]

$D=\frac{r}{6 f}$

[Eq. 3]

Table 4 compares the experimental data with theoretical values calculated from the three models considered here. None of these models can accurately predict the grain size of recrystallized grains. The Zener model underestimates the grain size for the Mn1 alloy, but overestimates for the rest of alloys. The grain size given by the Hellman-Hillert model approaches very closely the experimental values for the alloys containing low volume fractions of precipitates, but underestimation is still higher for the Mn1 alloy. Finally, the Rios model underestimates by far the grain size of all alloys. Discrepancies among experimental and theoretical data can result from different aspects not considered in the models: (i) The pinning effect of long strings of second 
phases is not considered. Micrographs show that these strings act as effective barriers for grain coarsening in neighboring dendrites. This explains the smallest grain size of the CeMM3.5 alloy, in spite of the volume fraction of fine precipitates is much lower compared to the Mn1 alloy. (ii) Heterogeneity of strain in the magnesium matrix, as inferred from the presence of coarse unrecrystallized grains. And (iii) Recrystallized grains are not in the equilibrium state. Probably in steady state the grain size would approach more the values predicted by the Zener model.

\section{Conclusions}

The following conclusions can be drawn from the present study:

1) Combination of in-situ HEXRD and DSC techniques have been employed here to identify the different transformations occurring during heating/cooling of the Mg-6Zn-1Y alloy, when this alloy is modified by small additions of calcium, manganese or cerium-rich mischmetal.

- The existence of the I-phase is not altered by manganese addition.

- Solidification leads to I-phase formation through direct eutectic reaction without prior formation of W-phase. During heating in DSC tests, I-phase transforms directly into Wphase.

- Calcium addition modifies the equilibrium phase diagram, preventing the formation of the I-phase. The W-phase is the first second phase solidifying at the interdendritic regions while $\mathrm{Mg}_{6} \mathrm{Zn}_{3} \mathrm{Ca}_{2}$ solidifies at the remaining interdendritic regions during further cooling. 
- CeMM addition promotes the formation of high volume fraction of T-phase and minor amounts of W-phase.

2) The recrystallization degree depends on the extrusion pressure, which in turn it is given by the volume fraction and brittleness of the second phases present in the as-cast billets.

3) Marked basal texture arises from non-recrystallized regions. Calcium addition, however, promotes almost complete recrystallization of the alloy during extrusion, weakening the overall texture.

\section{Acknowledgements}

We would like to acknowledge financial support of the Spanish Ministry of Economy and Competitiveness under project number MAT2012-34135. We would like to acknowledge the expert support of A. García and A. Tomás for assistance with TEM and SEM. We also would like to acknowledge the support of M. Acedo and Dr. F.A. López for assistance with the extrusion processing and conventional DSC experiments, respectively. The Deutches Elektronen-Synchrotron DESY is acknowledged for the provision of beamtime at the P07 beamline of the Petra III synchrotron facility in the framework of proposal I-20140198 EC.

\section{References}

[1] B.L. Mordike, T. Ebert, Magnesium Properties - applications - potential, Mater. Sci. Eng. A 302 (2001) 37-45. doi:10.1016/S0921-5093(00)01351-4.

[2] A.A. Luo, Recent magnesium alloy development for elevated temperature applications, Int. Mater. Rev. 49 (2004) 13-30. doi:10.1179/095066004225010497.

[3] J.Y. Lee, D.H. Kim, H.K. Lim, D.H. Kim, Effects of $Z n / Y$ ratio on microstructure and mechanical properties of Mg-Zn-Y alloys, Mater. Lett. 59 (2005) 3801-3805. doi:10.1016/j.matlet.2005.06.052. 
[4] D.K. Xu, L. Liu, Y.B. Xu, E.H. Han, The influence of element $Y$ on the mechanical properties of the as-extruded Mg-Zn-Y-Zr alloys, J. Alloys Compd. 426 (2006) 155-161. doi:10.1016/j.jallcom.2006.02.035.

[5] E. Oñorbe, G. Garcés, P. Pérez, P. Adeva, Effect of the LPSO volume fraction on the microstructure and mechanical properties of Mg-Y2X-ZnX alloys, J. Mater. Sci. 47 (2012) 1085-1093. doi:10.1007/s10853-011-5899-4.

[6] S. González, G. Garcés, P.Adeva, P.Pérez, Influence of processing route on microstructure and mechanical properties of Mg-Ni-Y-RE alloys, Mater. Charact. 64 (2012) 53-61. doi:10.1016/j.matchar.2011.12.001.

[7] R.G. Li, H.J. Zhang, G.Y. Fu, Microstructure and mechanical properties of extruded Mg96Zn1Y3 alloy, Mater. Charact. 98 (2014) 107-112. doi:10.1016/j.matchar.2014.10.016.

[8] D.H. Bae, M.H. Lee, K.T. Kim, W.T. Kim, D.H. Kim, Application of quasicrystalline particles as a strengthening phase in Mg-Zn-Y alloys, J. Alloys Compd. 342 (2002) 445-450. doi:10.1016/S0925-8388(02)00273-6.

[9] Y. Zhang, X. Zeng, L. Liu, C. Lu, H. Zhou, Q. Li, et al., Effects of yttrium on microstructure and mechanical properties of hot-extruded Mg-Zn-Y-Zr alloys, Mater. Sci. Eng. A 373 (2004) 320327. doi:10.1016/j.msea.2004.02.007.

[10] G. Yuan, H. Kato, K. Amiya, A. Inoue, Excellent creep properties of Mg-Zn-Cu-Gd-based alloy strengthened by quasicrystals and Laves phases, J. Mater. Res. 20 (2005) 1278-1286. doi:10.1557/JMR.2005.0156.

[11] D.H. Bae, Y. Kim, I.J. Kim, Thermally stable quasicrystalline phase in a superplastic Mg-Zn-Y-Zr alloy, Mater. Lett. 60 (2006) 2190-2193. doi:10.1016/j.matlet.2005.12.096.

[12] A. Müller, G. Garcés, P. Pérez, P. Adeva, Grain refinement of Mg-Zn-Y alloy reinforced by an icosahedral quasicrystalline phase by severe hot rolling, J. Alloys Compd. 443 (2007) 1-5. doi:10.1016/j.jallcom.2006.10.006.

[13] E. Mora, G. Garcés, E. Oñorbe, P. Pérez, P. Adeva, High-strength Mg-Zn-Y alloys produced by powder metallurgy, Scr. Mater. 60 (2009) 776-779. doi:10.1016/j.scriptamat.2009.01.012.

[14] A. Singh, Y. Osawa, H. Somekawa, T. Mukai, Ultra-fine grain size and isotropic very high strength by direct extrusion of chill-cast $\mathrm{Mg}-\mathrm{Zn}-\mathrm{Y}$ alloys containing quasicrystal phase, Scr. Mater. 64 (2011) 661-664. doi:10.1016/j.scriptamat.2010.12.016.

[15] T. Ebert ,K.U. Kainer, Rapid Solidification and Special Processes for Processing Magnesium Alloys, K.U. Kainer editor, Magnesium - Alloys and Technology (2003) 164-183. doi: 10.1002/3527602046.ch10.

[16] S. Guan, J. Hu, L. Wang, S. Zhu, H. Wang, J. Wang et al., Mg Alloys Development and Surface Modification for Biomedical Application, Frank Czerwinski editor, Magnesium Alloys Corrosion and Surface Treatments (2009) 109-152. doi: 10.5772/13187. 
[17] P. Pérez, S. González, G. Garcés, P. Adeva, Influence of mischmetal composition on crystallization and mechanical properties of Mg80-Ni10-MM10 alloys, Intermetallics 17 (2009) 504-511. doi:10.1016/j.intermet.2009.01.001.

[18] K. Milička, P. Pérez, F. Dobeš, G. Garcés, P. Adeva, Creep of high-strength Mg-Ni-Y-RE alloys, Mater. Sci. Eng. A 510-511 (2009) 377-381. doi:10.1016/j.msea.2008.06.059.

[19] S. Golmakaniyoon, R. Mahmudi, Microstructure and creep behavior of the rare-earth doped Mg-6Zn-3Cu cast alloy, Mater. Sci. Eng. A 528 (2011) 1668-1677. doi:10.1016/j.msea.2010.10.095.

[20] D.F. Zhang, F.G. Qi, W. Lan, G.L. Shi, X.B. Zhao, Effects of Ce addition on microstructure and mechanical properties of Mg-6Zn-1Mn alloy, Trans. Nonferrous Met. Soc. China 21 (2011) 703-710. doi:10.1016/S1003-6326(11)60769-3.

[21] P. Pérez, J. Medina, G. Garcés, P. Adeva, Influence of Y/CeMM ratio on the microstructure and mechanical properties of Mg 95Zn2(Y,CeMM)3 alloys, Intermetallics 31 (2012) 196-201. doi:10.1016/j.intermet.2012.07.005.

[22] J. Bohlen, J. Wendt, M. Nienaber, K.U. Kainer, L. Stutz, D. Letzig, Calcium and zirconium as texture modifiers during rolling and annealing of magnesium-zinc alloys, Mater. Charact. 101 (2015) 144-152. doi:10.1016/j.matchar.2015.02.002.

[23] S.A. Khan, Y. Miyashita, Y. Mutoh, Z. Bin Sajuri, Influence of Mn content on mechanical properties and fatigue behavior of extruded Mg alloys, Mater. Sci. Eng. A 420 (2006) 315-321. doi:10.1016/j.msea.2006.01.091.

[24] W. Diqing, W. Jincheng, W. Gaifang, C. Xianyi, Linlin, F. Zhigang, et al., Effect of Mn on damping capacities, mechanical properties, and corrosion behaviour of high damping Mg-3 wt.\%Ni based alloy, Mater. Sci. Eng. A 494 (2008) 139-142. doi:16/j.msea.2008.04.011.

[25] X. Zeng, Y. Zhang, C. Lu, W. Ding, Y. Wang, Y. Zhu, Precipitation behavior and mechanical properties of a $\mathrm{Mg}-\mathrm{Zn}-\mathrm{Y}-\mathrm{Zr}$ alloy processed by thermo-mechanical treatment, J. Alloys Compd. 395 (2005) 213-219. doi:10.1016/j.jallcom.2004.10.070.

[26] M. Hradilová, D. Vojtěch, J. Kubásek, J. Čapek, M. Vlach, Structural and mechanical characteristics of $\mathrm{Mg}-4 \mathrm{Zn}$ and $\mathrm{Mg}-4 \mathrm{Zn}-0.4 \mathrm{Ca}$ alloys after different thermal and mechanical processing routes, Mater. Sci. Eng. A 586 (2013) 284-291. doi:10.1016/j.msea.2013.08.008.

[27] Y.Z. Du, M.Y. Zheng, X.G. Qiao, K. Wu, X.D. Liu, G.J. Wang, et al., Microstructure and mechanical properties of $\mathrm{Mg}-\mathrm{Zn}-\mathrm{Ca}-\mathrm{Ce}$ alloy processed by semi-continuous casting, Mater. Sci. Eng. A 582 (2013) 134-139. doi:10.1016/j.msea.2013.06.027.

[28] Q. Li, Q. Wang, Y. Wang, X. Zeng, W. Ding, Effect of Nd and Y addition on microstructure and mechanical properties of as-cast Mg-Zn-Zr alloy, J. Alloys Compd. 427 (2007) 115-123. doi:10.1016/j.jallcom.2006.02.054. 
[29] J. Yang, J. Wang, L. Wang, Y. Wu, L. Wang, H. Zhang, Microstructure and mechanical properties of Mg-4.5Zn-xNd (x=0, 1 and 2, wt\%) alloys, Mater. Sci. Eng. A 479 (2008) 339344. doi:10.1016/j.msea.2007.06.057.

[30] M.L. Huang, H.X. Li, H. Ding, Y.P. Ren, G.W. Qin, S.M. Hao, Partial phase relationships of MgZn-Ce system at $350^{\circ} \mathrm{C}$, Trans. Nonferrous Met. Soc. China (English Ed.) 19 (2009) 681-685. doi:10.1016/S1003-6326(08)60333-7.

[31] T.Zhou, H. Xia, Z.H. Chen, Effect of Ce on microstructures and mechanical properties of rapidly solidified Mg-Zn alloy, Mater. Sci. Technol. 27 (2011) 1198-1205. doi: 10.1179/026708310X12683158443242.

[32] H. Huang, Y. Tian, G. Yuan, C. Chen, Z. Wang, W. Ding, et al., Secondary phases in quasicrystalreinforced Mg-3.5Zn-0.6Gd Mg alloy, Mater. Charact. 108 (2015) 132-136. doi:10.1016/j.matchar.2015.09.005.

[33] Y.N. Zhang, D. Kevorkov, J. Li, E. Essadiqi, M. Medraj, Determination of the solubility range and crystal structure of the Mg-rich ternary compound in the Ca-Mg-Zn system, Intermetallics 18 (2010) 2404-2411. doi:10.1016/j.intermet.2010.08.033.

[34] M.L. Huang, H.X. Li, H. Ding, L. Bao, X. Bin Ma, S.M. Hao, Intermetallics and phase relations of Mg-Zn-Ce alloys at $400^{\circ} \mathrm{C}$, Trans. Nonferrous Met. Soc. China 22 (2012) 539-545. doi:10.1016/S1003-6326(11)61211-9.

[35] L.Y. Wei, G.L. Dunlop, Crystal symmetry of the pseudo-ternary T-phases in Mg-Zn-rare earth alloys, J. Mater. Sci. Lett. 15 (1996) 4-7. doi:10.1007/BF01855594.

[36] L.Y. Wei, G.L. Dunlop, H. Westengen, Solidification behaviour and phase constituents of cast Mg-Zn-mischmetal alloys, J. Mater. Sci. 32 (1997) 3335-3340. doi:10.1023/a:1018695927717.

[37] D.K. Xu, E. Han, L. Liu, Y.B. Xu, Influence of Higher Zn / Y Ratio on the Microstructure and Mechanical Properties of Mg-Zn-Y-Zr Alloys, Metall. Mater. Trans. A. 40 (2009) 1727-1740. doi:10.1007/s11661-009-9817-1.

[38] G. Effenberg, F.Aldinger, P.Rogl, Ternary Alloys: A Comprehensive Compendium of Evaluated Constitutional Data and Phase Diagrams, Vol. 18, MSI, Stuttgart (2001) 702-710.

[39] J. Gro, A. Kozlov, X.Y. Fang, J. Geng, J.F. Nie, R. Schmid-fetzer, Phase equilibria and transformations in ternary Mg-rich Mg - Y - Zn alloys, Acta Mater. 60 (2012) 5948-5962. doi:10.1016/j.actamat.2012.05.035.

[40] S.A. Farzadfar, M. Sanjari, I.-H. Jung, E. Essadiqi, S. Yue, Experimental and calculated phases in two as-cast and annealed Mg-Zn-Y alloys, Mater. Charact. 63 (2012) 9-16. doi:10.1016/j.matchar.2011.10.015. 
[41] J.F. Liu, Z.Q. Yang, H.Q. Ye, In situ transmission electron microscopy investigation of quasicrystal-crystal transformations in Mg-Zn-Y alloys, J. Alloys Compd. 621 (2015) 179-188. doi:10.1016/j.jallcom.2014.09.177.

[42] E.A. Ball, P.B. Prangnell, Tensile-compressive yield asymmetries in high strength wrought magnesium alloys, Scr. Mater. 31 (1994) 111-116. doi:10.1016/0956-716X(94)90159-7.

[43] N. Stanford, M.R. Barnett, The origin of "rare earth" texture development in extruded Mgbased alloys and its effect on tensile ductility, Mater. Sci. Eng. A 496 (2008) 399-408. doi:10.1016/j.msea.2008.05.045.

[44] M. Huppmann, S. Gall, S. Müller, W. Reimers, Changes of the texture and the mechanical properties of the extruded Mg alloy ME21 as a function of the process parameters, Mater. Sci. Eng. A 528 (2010) 342-354. doi:10.1016/j.msea.2010.09.025.

[45] N. Stanford, Micro-alloying Mg with $\mathrm{Y}, \mathrm{Ce}, \mathrm{Gd}$ and La for texture modification - A comparative study, Mater. Sci. Eng. A 527 (2010) 2669-2677. doi:10.1016/j.msea.2009.12.036.

[46] J.D. Robson, D.T. Henry, B. Davis, Particle effects on recrystallization in magnesiummanganese alloys: Particle pinning, Mater. Sci. Eng. A 528 (2011) 4239-4247. doi:10.1016/j.msea.2011.02.030.

[47] C.S. Smith, Grains, phases, and interphases: an interpretation of microstructure, Metall. Mater. Trans. A 175 (1948) 15-51. doi:10.1007/s11661-010-0215-5.

[48] P. Hellman, M. Hillert, On the effect of second-phase particles in grain growth, Scand. J. Metall. 4 (1975) 211-219.

[49] P.R. Rios, A Theory Pinning for Grain Boundary, Acta. Metall. 35 (1987) 2805-2814. doi:10.1016/0001-6160(87)90280-X.

\section{Table captions:}

Table 1: Nominal composition (wt. \%) and chemical composition determined by micro X-Ray fluorescence (wt. \%) and designation of $\mathrm{Mg}-\mathrm{Zn}-\mathrm{Y}$ alloys.

\begin{tabular}{|l|l|l|l|l|l|l|l|l|l|l|l|l|l|}
\hline \multirow{2}{*}{$\begin{array}{l}\text { Alloy } \\
\text { designation }\end{array}$} & \multicolumn{4}{|c|}{ Nominal composition (wt. \%) } & \multicolumn{3}{c|}{ X-Ray fluorescence results (wt. \%) } \\
\cline { 2 - 15 } & Mg & Zn & Y & Mn & Ca & CeMM & Mg & Zn & Y & Mn & Ca & CeMM \\
\hline 6-1 & 93.0 & 6.0 & 1.0 & - & - & - & 93.0 & 6.0 & 1.0 & - & - & - \\
\hline Mn1 & 92.0 & 6.0 & 1.0 & 1.0 & - & - & 90.6 & 7.4 & 1.0 & 1.0 & - & - \\
\hline Ca1 & 92.0 & 6.0 & 1.0 & - & 1.0 & - & 92.0 & 6.3 & 0.9 & - & 0.8 & - \\
\hline CeMM3.5 & 89.5 & 6.0 & 1.0 & - & - & 3.5 & 89.5 & 6.6 & 1.0 & - & - & 2.9 \\
\hline
\end{tabular}


Table 2: Temperature of transformations observed in Mg-Zn-Y cast alloys.

\begin{tabular}{|l|c|c|c|}
\hline \multicolumn{1}{|c|}{ Alloy } & Peak $1\left(^{\circ} \mathrm{C}\right)$ & Peak $2\left({ }^{\circ} \mathrm{C}\right)$ & Peak 3 $\left({ }^{\circ} \mathrm{C}\right)$ \\
\hline Cast 6-1 & 452 & 505 & 629 \\
\hline Cast Mn1 & 456 & 488 & 623 \\
\hline Cast Ca1 & 396 & 468 & 619 \\
\hline Cast CeMM3.5 & 504 & 536 & 615 \\
\hline
\end{tabular}

Table 3: Microstructural features found in the Mg-Zn-Y alloys: second phases present in the alloy, volume fraction of coarse second phases, size of coarse second phases, volume fraction of precipitates, size of precipitates, volume fraction of non-recrystallized areas, grain size of recrystallized grains and maximum intensity of macrotexture measurements (I).

\begin{tabular}{|c|c|c|c|c|c|c|c|c|c|}
\hline Alloy & $\begin{array}{l}\text { Second } \\
\text { phases }\end{array}$ & $\begin{array}{l}\text { Vol.fract. } \\
\text { coarse } \\
\text { second } \\
\text { phases } \\
(\%)\end{array}$ & $\begin{array}{l}\text { Size } \\
\text { coarse } \\
\text { second } \\
\text { phases } \\
(\mu \mathrm{m})\end{array}$ & $\begin{array}{l}\text { Vol.fract. } \\
\text { fine } \\
\text { particles } \\
\text { (\%) }\end{array}$ & $\begin{array}{l}\text { Size fine } \\
\text { particles } \\
(\mathrm{nm})\end{array}$ & $\begin{array}{l}\text { Vol.fract. } \\
\text { UnDRX } \\
\text { areas (\%) }\end{array}$ & $\begin{array}{l}\text { Grain } \\
\text { size } \\
(\mu \mathrm{m})\end{array}$ & $\begin{array}{l}\text { Grain } \\
\text { structure }\end{array}$ & 1 \\
\hline 6-1 & I-Phase & $5.8 \pm 0.7$ & $0.6 \pm 0.1$ & $0.17 \pm 0.01$ & $18 \pm 1$ & $6.4 \pm 0.9$ & $3.6 \pm 0.1$ & bimodal & 9 \\
\hline Mn1 & $\begin{array}{c}\text { I-Phase } \\
\text { Mn- } \\
\text { containing } \\
\text { particles }\end{array}$ & $7.8 \pm 1.4$ & $1.0 \pm 0.2$ & $1.32 \pm 0.02$ & $18 \pm 1$ & $8.4 \pm 1.2$ & $2.1 \pm 0.1$ & bimodal & 9 \\
\hline Ca1 & $\begin{array}{l}\text { W-Phase } \\
\mathrm{Mg}_{6} \mathrm{Zn}_{3} \mathrm{Ca}_{2}\end{array}$ & $8.3 \pm 1.2$ & $1.2 \pm 0.3$ & $0.25 \pm 0.02$ & $30 \pm 2$ & $1.8 \pm 0.6$ & $4.4 \pm 0.1$ & equiaxial & 3 \\
\hline $\begin{array}{l}\text { CeMM } \\
3.5\end{array}$ & $\begin{array}{l}\text { W-phase } \\
\text { T-phase }\end{array}$ & $14.3 \pm 2.5$ & $2.6 \pm 0.5$ & $0.13 \pm 0.01$ & $17 \pm 1$ & $5.8 \pm 0.5$ & $1.9 \pm 0.1$ & bimodal & 9 \\
\hline
\end{tabular}


Table 4: Comparison of experimental grain size with values predicted by Zener $\left(D_{Z}\right)$, Hillert $\left(D_{H}\right)$ and Rios $\left(D_{R}\right)$ models.

\begin{tabular}{|l|c|c|c|c|}
\hline Alloy & Grain size $(\mu \mathrm{m})$ & $\mathrm{D}_{\mathbf{Z}}(\mu \mathrm{m})$ & $\mathrm{D}_{\mathrm{H}}(\mu \mathrm{m})$ & $\mathrm{D}_{\mathrm{R}}(\mu \mathrm{m})$ \\
\hline $\mathbf{6 - 1}$ & $3.6 \pm 0.1$ & 7.0 & 3.0 & 0.9 \\
\hline Mn1 & $2.1 \pm 0.1$ & 0.9 & 0.5 & 0.1 \\
\hline Ca1 & $4.4 \pm 0.1$ & 8.0 & 3.5 & 1.0 \\
\hline CeMM3.5 & $1.9 \pm 0.1$ & 8.7 & 3.6 & 1.1 \\
\hline
\end{tabular}

\section{Figure captions:}

Fig. 1: Backscattered electron images of the as-cast alloys: (a) 6-1 alloy, (b) Mn1 alloy, (c) Ca1 alloy and (d) CeMM3.5 alloy.
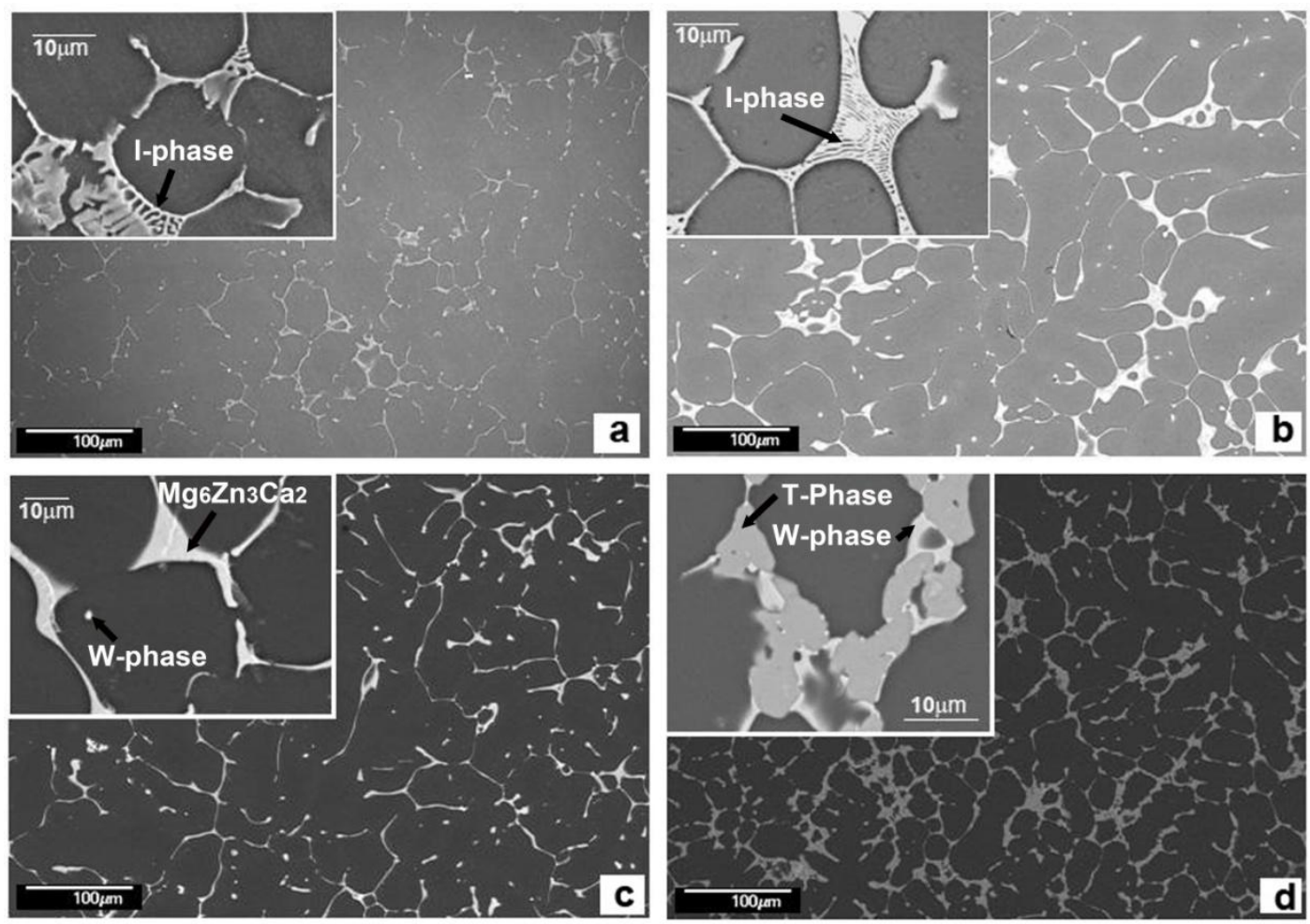
Fig. 2: DSC curves during heating at $20 \mathrm{k} / \mathrm{min}$ of cast alloys: (a) 6-1 alloy, (b) Mn1 alloy, (c) Ca1 alloy and (d) CeMM3.5 alloy.

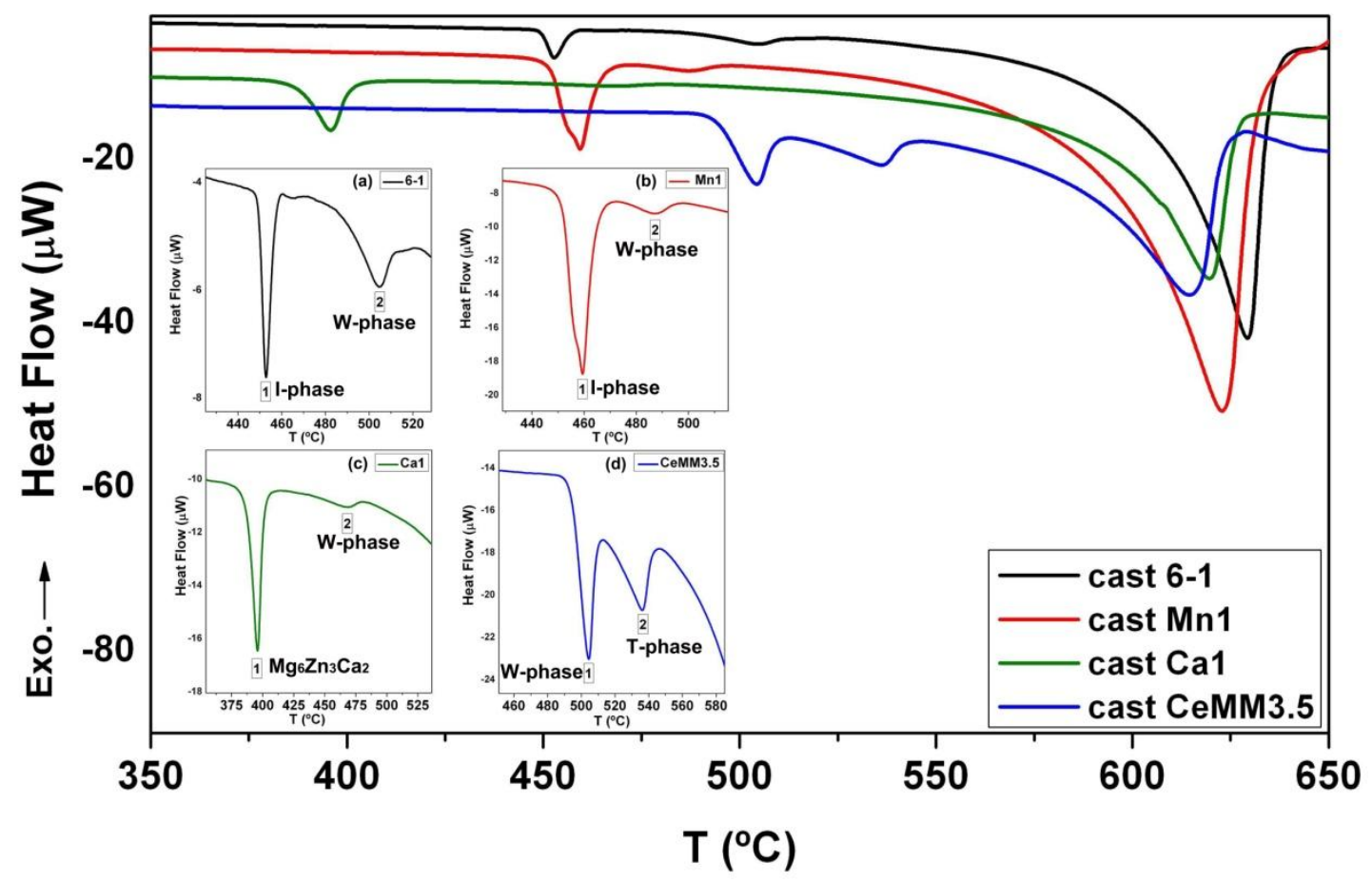


Fig. 3: Synchrotron diffraction patterns for (a) 6-1 alloy, (b) Mn1 alloy, (c) Ca1 alloy during heating from RT up to $500^{\circ} \mathrm{C}$ and synchrotron diffraction patterns for (d) CeMM3.5 alloy during heating from RT up to $550^{\circ} \mathrm{C}$. X-ray wavelength: $0.01424 \mathrm{~nm}$.
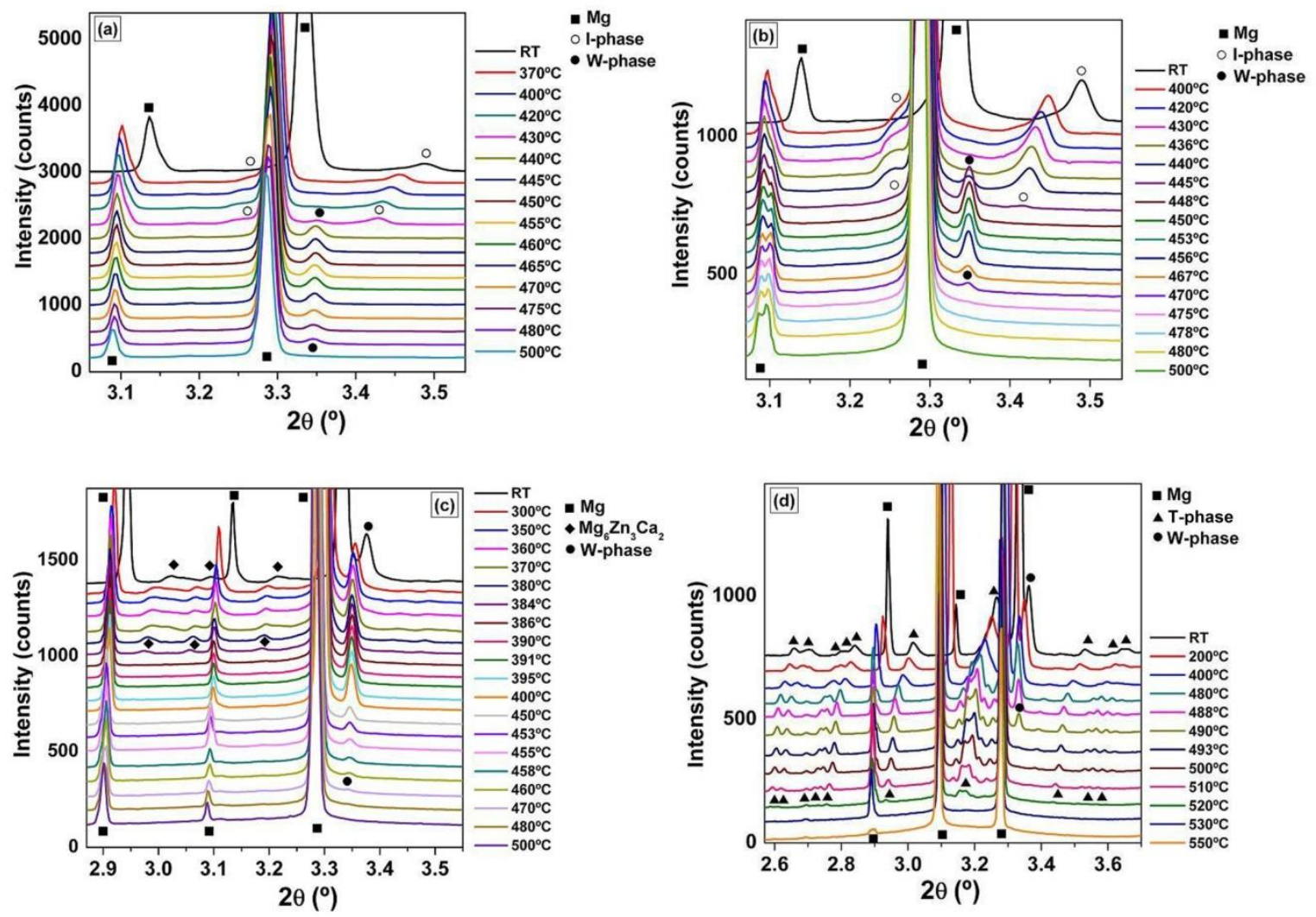
Fig. 4: Backscattered electron images of the alloys along the extrusion direction. (a) 6-1 alloy, (b) Mn1 alloy, (c) Ca1 alloy and (d) CeMM3.5 alloy.
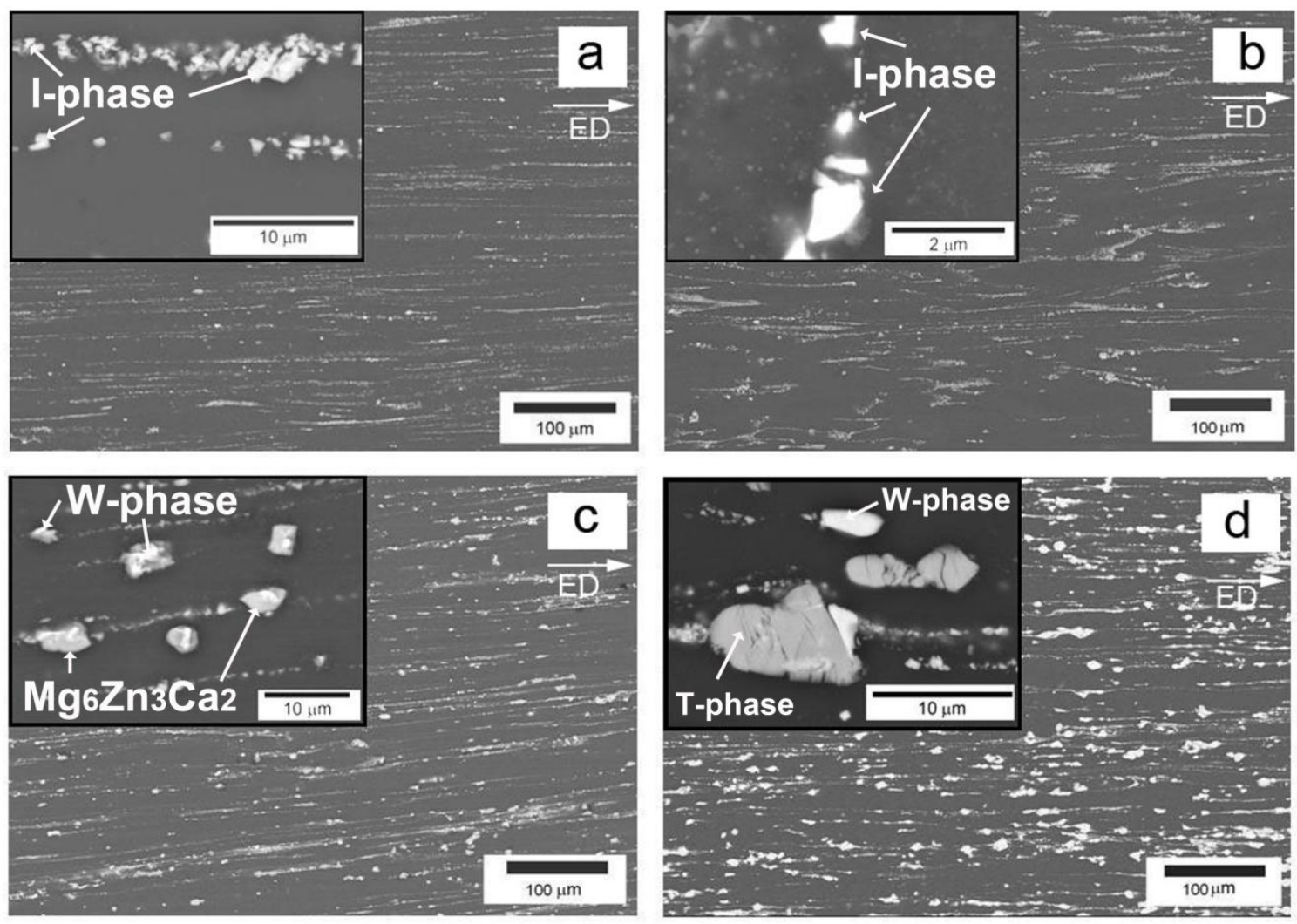
Fig. 5: XRD patterns corresponding to 6-1, Mn1, Ca1 and CeMM3.5 alloys ( $\mathbf{M g}$, $\bullet$ W-phase, O Iphase, $\diamond \mathrm{Mg}_{6} \mathrm{Zn}_{3} \mathrm{Ca}_{2}, \nabla \mathrm{Mn}$ and $\boldsymbol{\Delta} \mathrm{T}$-Phase).

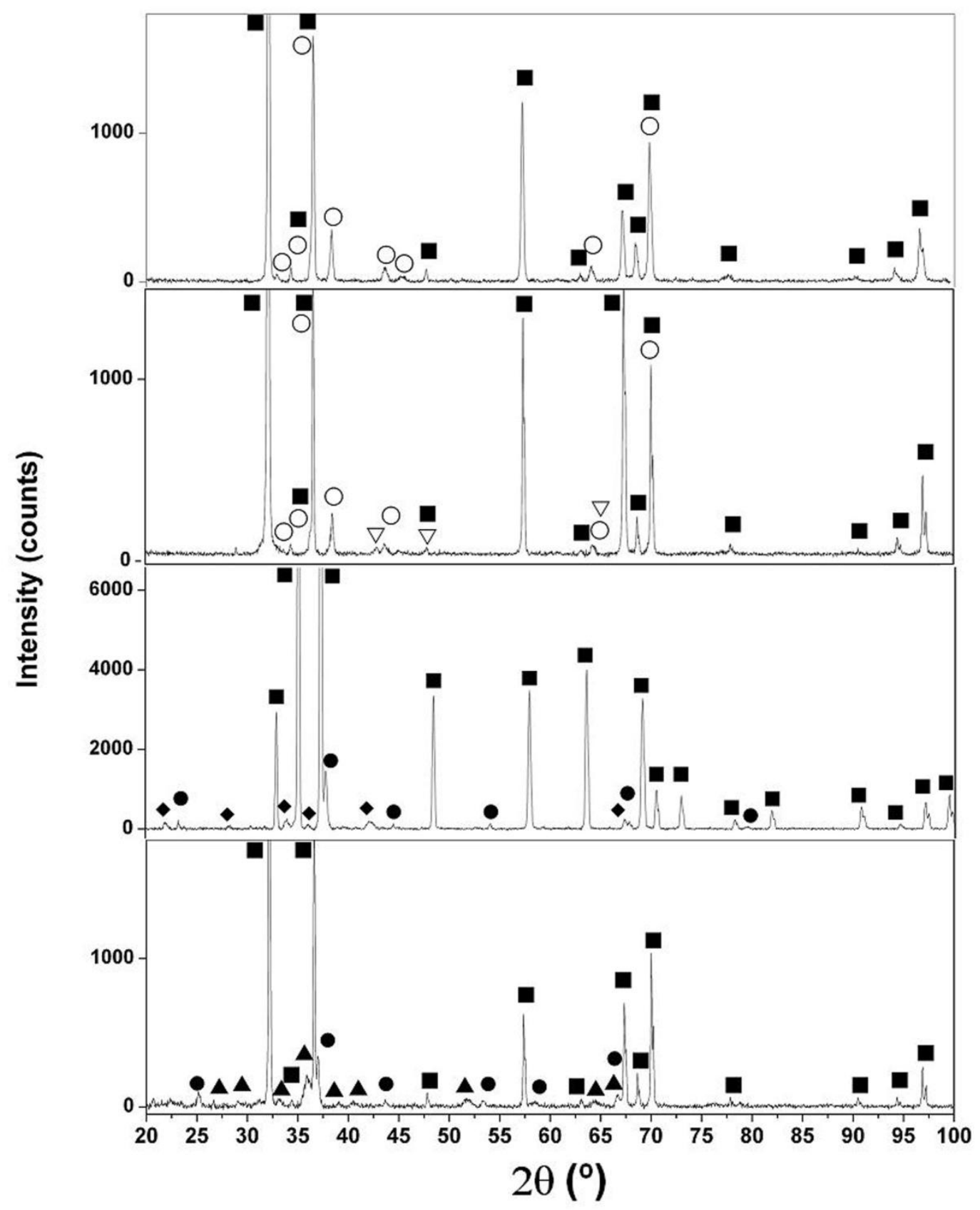


Fig. 6: (a) Bright-field TEM images of coarse I-phase particles at grain boundaries. The corresponding SADP of coarse particles with the three-fold symmetry of the I-phase is presented in the inset; (b) Bright-field TEM image of fine I-phase particles within the Mg grains of 6-1 alloy.
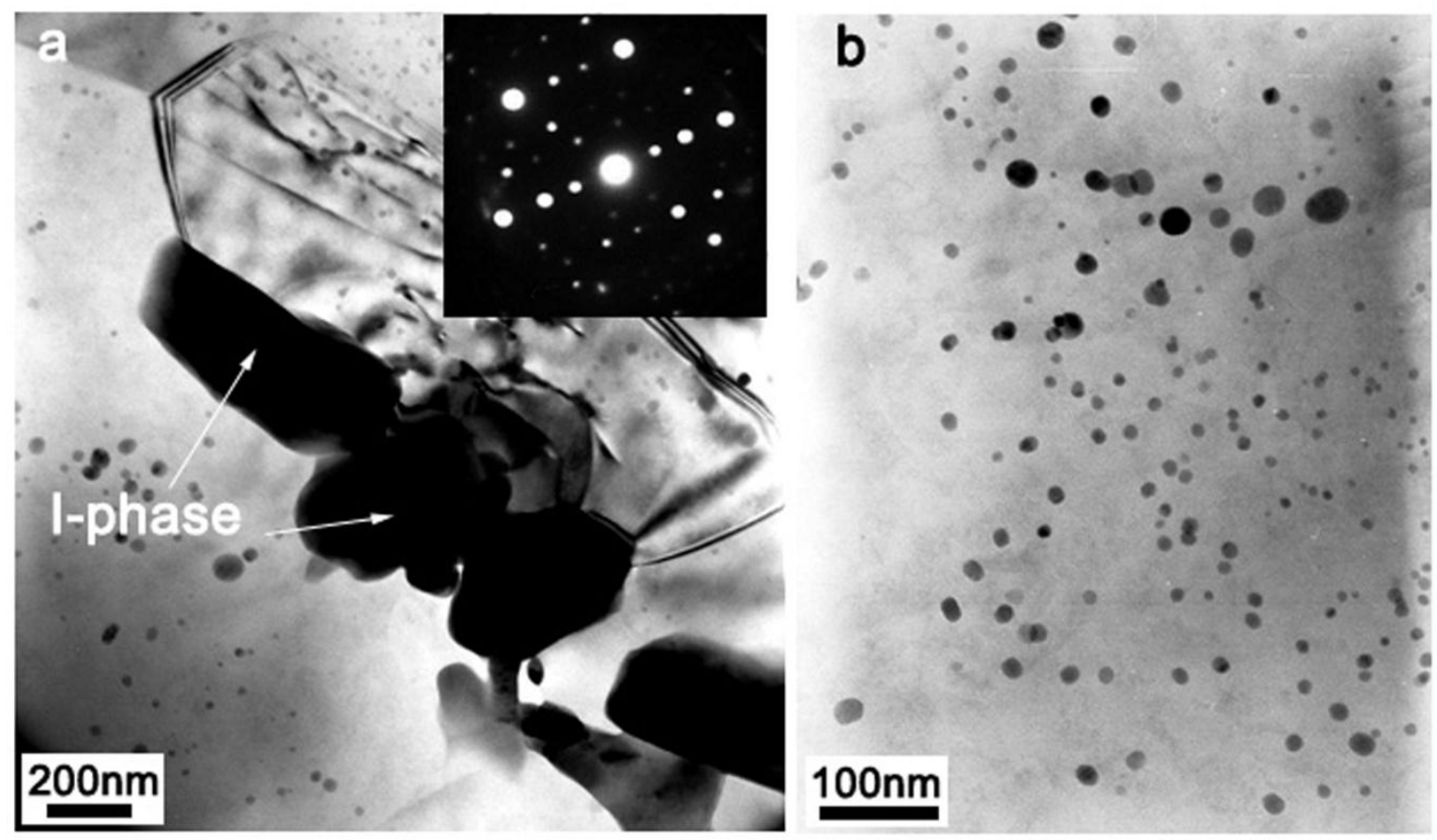
Fig. 7: (a) Bright-field TEM image of I-phase particles with the corresponding electron diffraction pattern of 5-fold symmetry (red arrows in the figure indicate the concentration of dislocations). (b, $\mathrm{c}$ and d) different morphology particles in $\mathrm{Mg}$ matrix of Mn1 alloy.

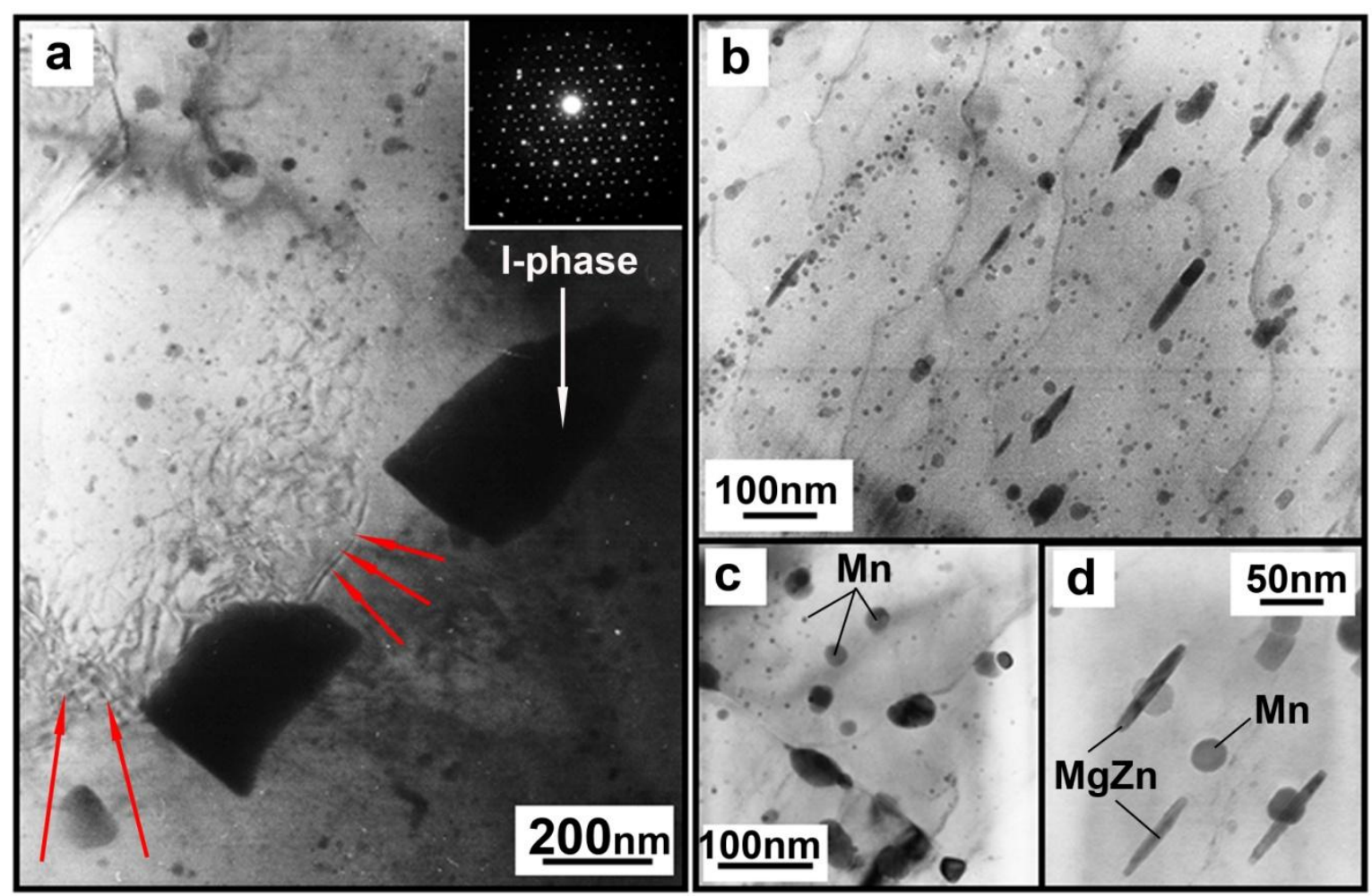


Fig. 8: (a) A bright field TEM image of the Ca1 alloy showing $\mathrm{Mg}_{6} \mathrm{Zn}_{3} \mathrm{Ca}_{2}$ particles and corresponding SAD pattern recorded along the zone axes of [0110] and [0111] , (b) TEM image of $W$-phase and corresponding SAD patterns recorded along the zone axes of [011] and [ $\overline{1} 11]$.

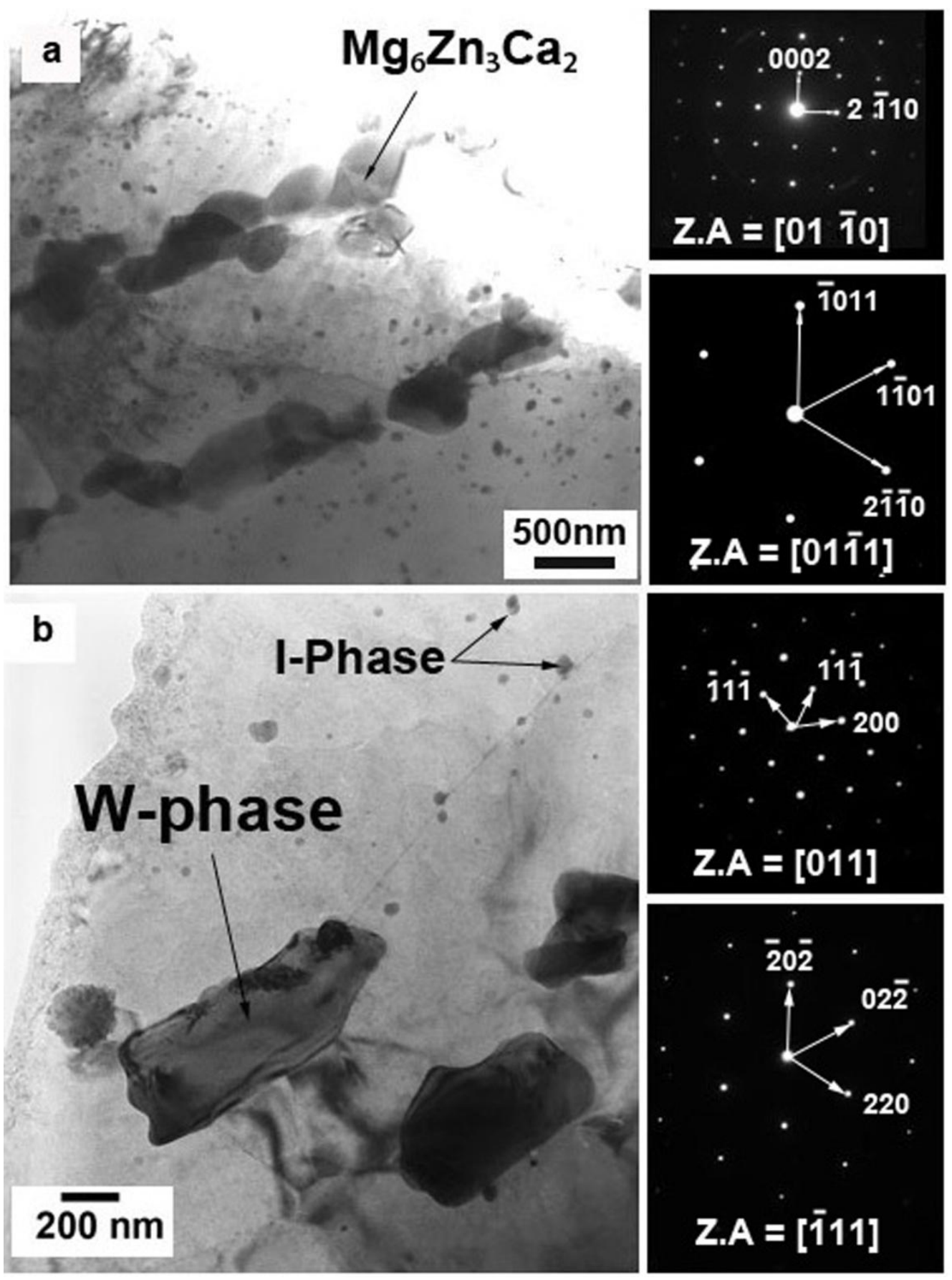


Fig. 9: (a) Bright field TEM image of coarse second phase particle enriched in cerium (T-phase) and the corresponding selected area diffraction pattern of the zone axes [011]. (b) Bright field TEM image of spherical particles enriched in $\mathrm{Zn}$ and $\mathrm{Y}$ of CeMM3.5 alloy.
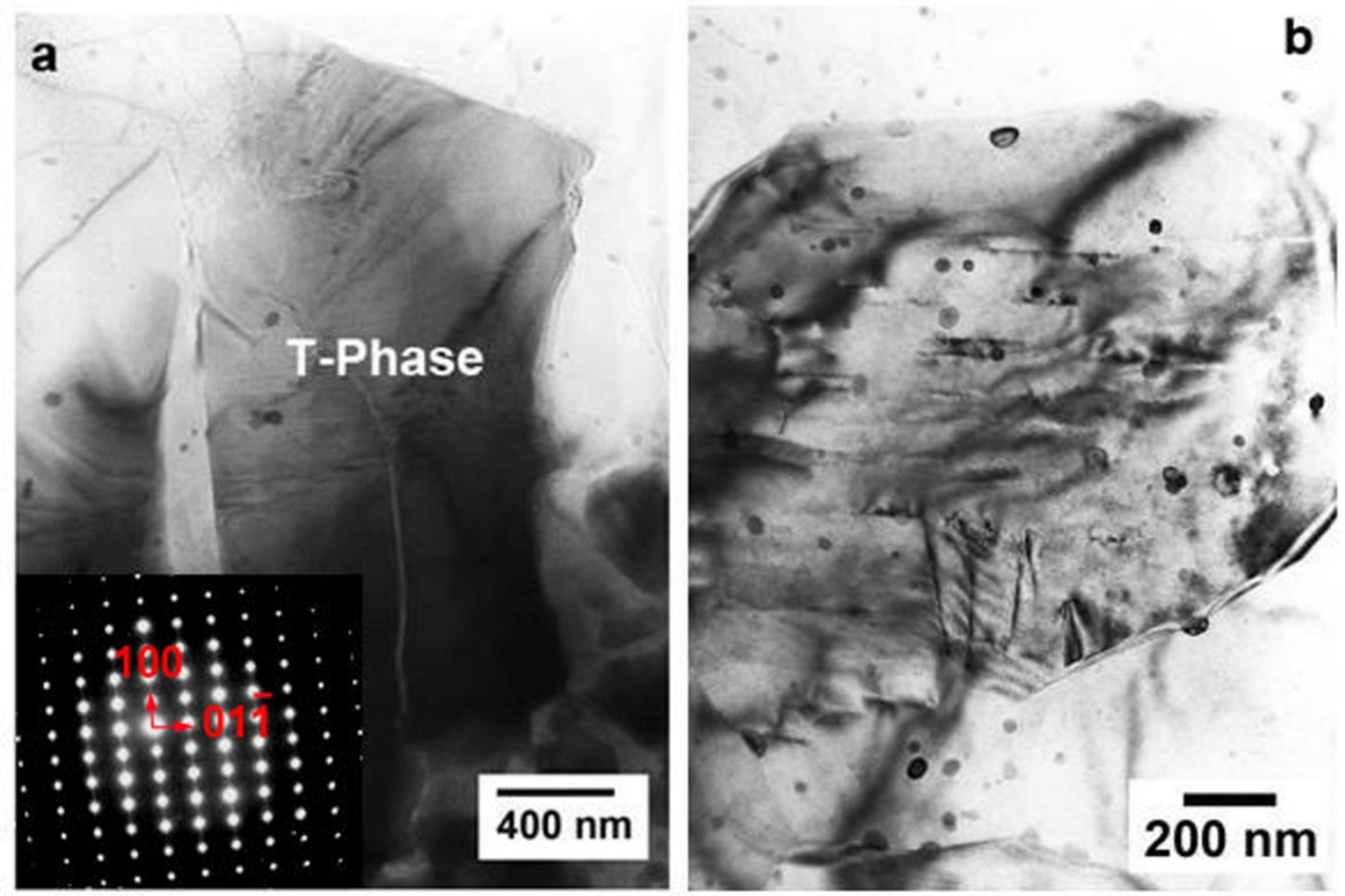
Fig. 10: Optical micrographs showing the etched samples: (a) 6-1 alloy, (b) Mn1 alloy, (c) CeMM3.5 alloy and (d) Ca1 alloy.
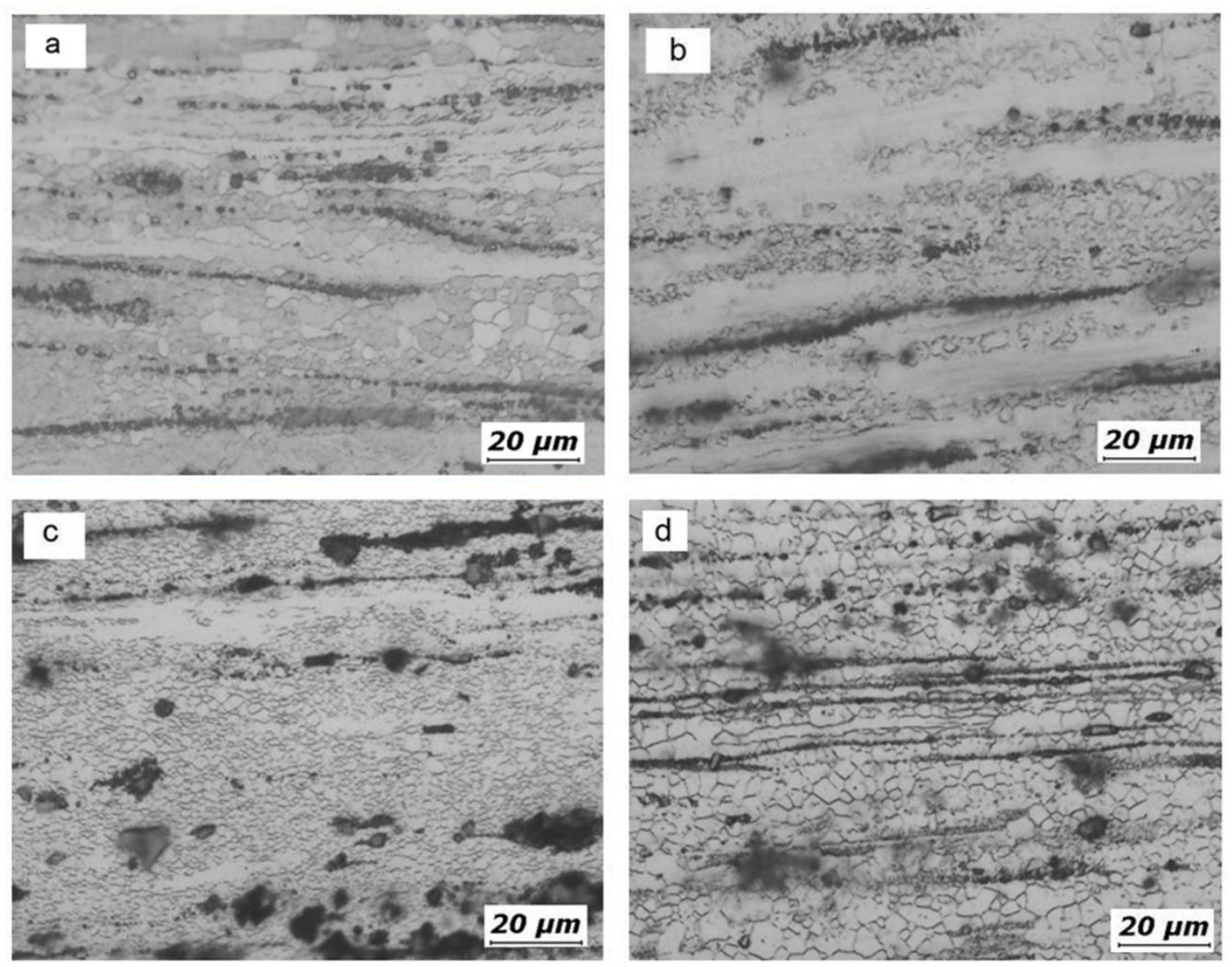
Fig. 11: Calculated pole figures in the basal plane $\{0001\}$ and prismatic plane $\{10 \overline{1} 0\}$ for the extruded alloys (a) 6-1 alloy, (b) Mn1 alloy, (c) Ca1 alloy and (d) CeMM3.5 alloy.

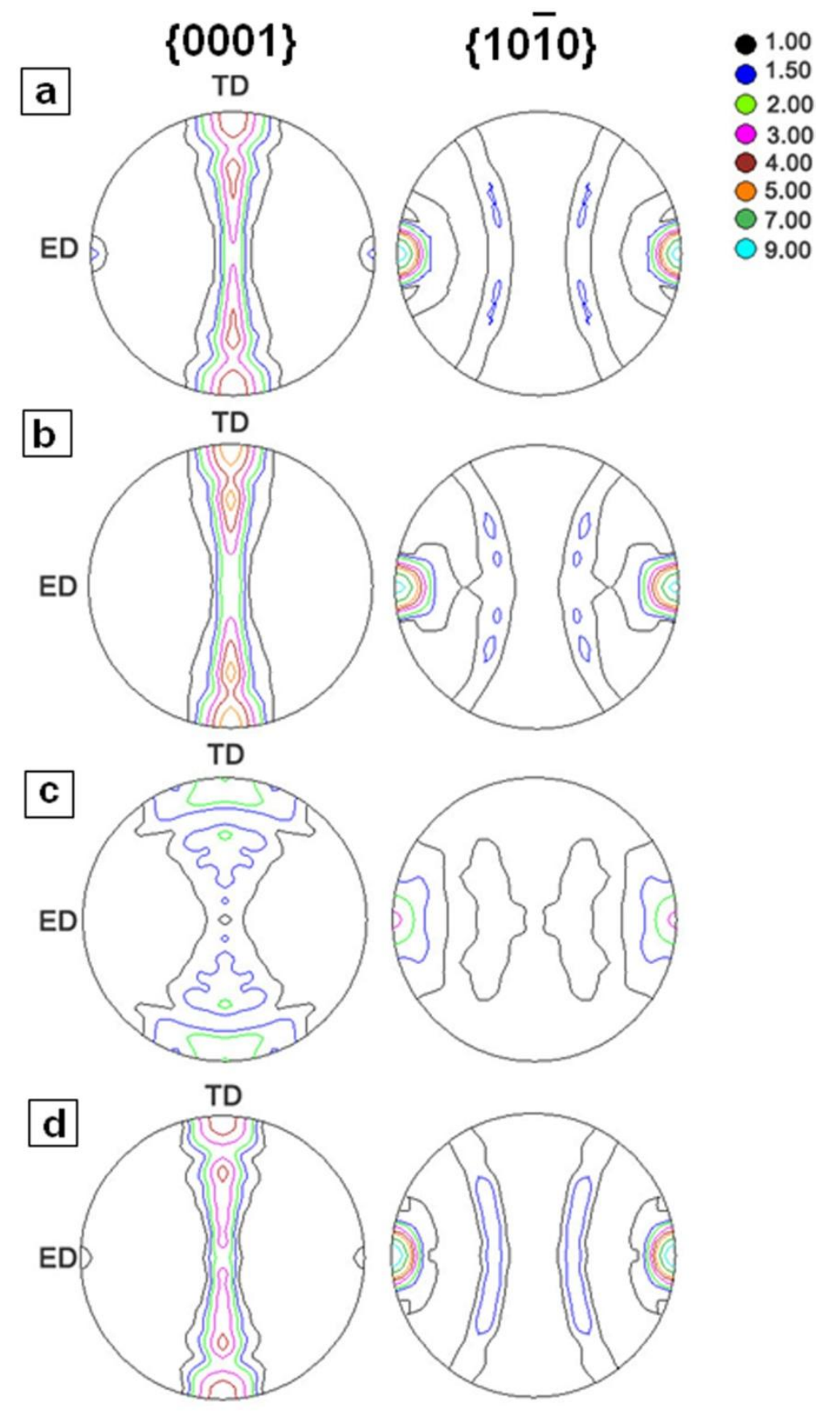


Fig. 12: Color key triangle, EBSD results showing Orientation Image Mapping (OIM) in the plane of ED-TD and pole figures of the extruded (a) 6-1 alloy, (b) Mn1 alloy, (c) Ca1 alloy and (d) CeMM3.5 alloy.
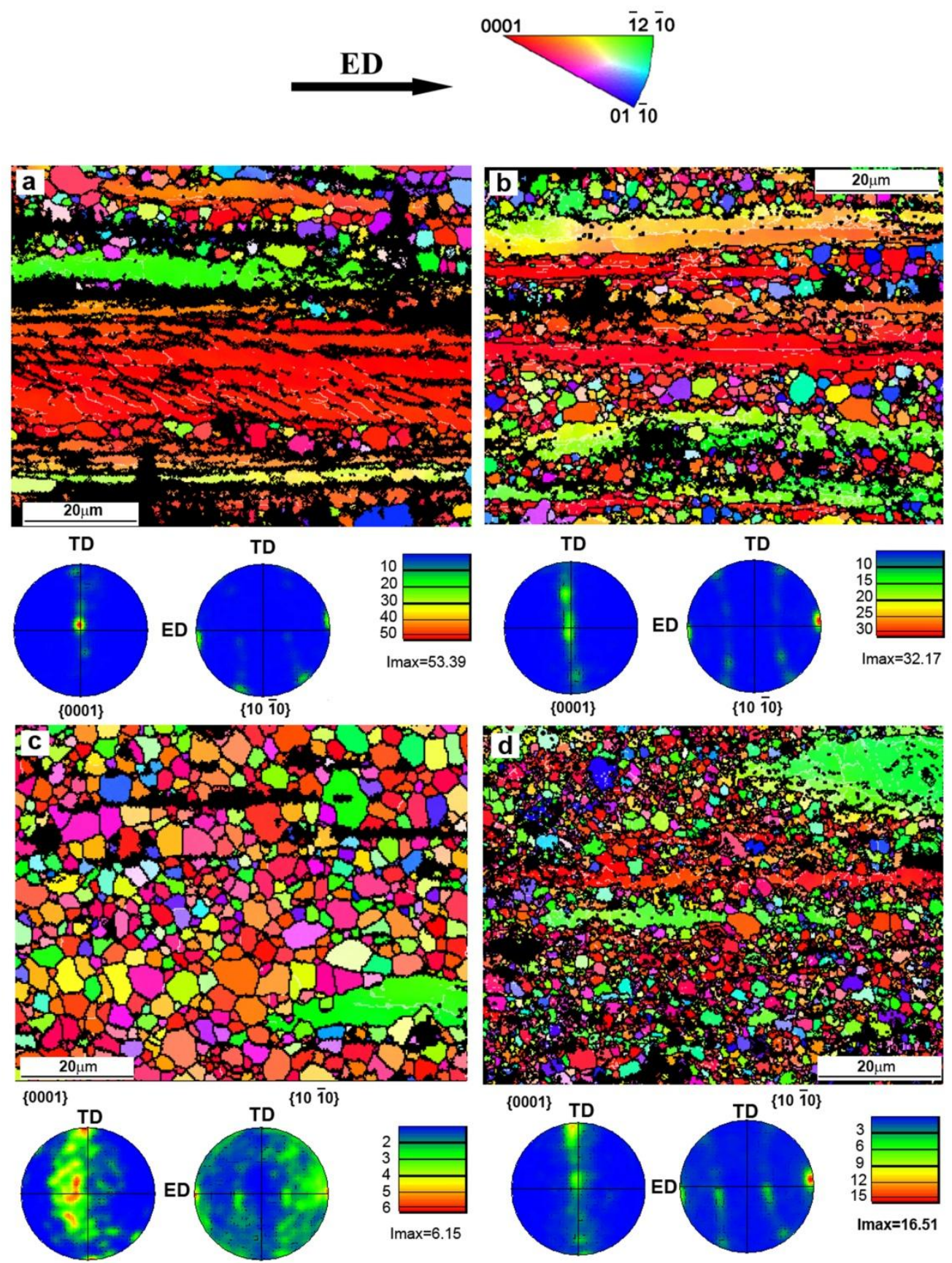